NBER WORKING PAPER SERIES

\title{
MODEST POLICY INTERVENTIONS
}

\author{
Eric M. Leeper \\ Tao Zha \\ Working Paper 9192 \\ http://www.nber.org/papers/w9192
NATIONAL BUREAU OF ECONOMIC RESEARCH 1050 Massachusetts Avenue
Cambridge, MA 02138
September 2002

We thank Ralph Bryant, Peter Clark, Tom Cooley, Jon Faust, John Geweke, Ross Levine, Adrian Pagan, Peter Pedroni, Tom Sargent, Anders Vredin, Mike Woodford, and especially David Gordon, Chris Sims, and Dan Waggoner for helpful suggestions. The views expressed herein are not necessarily those of the Federal Reserve Bank of Atlanta, the Federal Reserve System or the National Bureau of Economic Research.

(C) 2002 by Eric M. Leeper and Tao Zha. All rights reserved. Short sections of text, not to exceed two paragraphs, may be quoted without explicit permission provided that full credit, including $\mathbb{C}$ notice, is given to the source. 
Modest Policy Interventions

Eric M. Leeper and Tao Zha

NBER Working Paper No. 9192

September 2002

JEL No. E52, E47, C53

\begin{abstract}
We present a framework for computing and evaluating linear projections of macro variables conditional on hypothetical paths of monetary policy. A modest policy intervention is a change in policy that does not significantly shift agents' beliefs about policy regime and does not generate quantitatively important expectations-formation effects of the kind Lucas (1976) emphasizes. The framework is applied to an econometric model of U.S. postwar monetary policy behavior. It finds that a rich class of interventions routinely considered by the Federal Reserve are modest and their impacts can be reliably forecasted by an accurately identified linear model. Moreover, modest interventions can matter: they may shift the projected paths and probability distributions of macro variables in economically meaningful ways.
\end{abstract}

Eric M. Leeper

Indiana University

Department of Economics

105 Wylie Hall

Bloomington, IN 47405

and NBER

eleeper@indiana.edu
Tao Zha

Federal Reserve Bank of Atlanta 1000 Peachtree Street, N.E. Atlanta, GA 30309

tao.zha@atl.frb.org 


\title{
Modest Policy Interventions
}

\author{
Eric M. Leeper and Tao Zha*
}

\section{Introduction}

This paper presents a framework for computing and evaluating linear projections of macro variables conditional on hypothetical paths of monetary policy. The framework includes a theoretical model that reports when linear projections are reliable even though policy switches from one regime to another. Insights from the theory are applied to an empirical model of U.S. monetary policy behavior to probe the range of policy interventions that do not generate quantitatively important expectations-formation effects of the kind Lucas (1976) emphasizes.

We assume that in the true economy policy regime evolves randomly according to a Markov chain where regime is a hidden state variable. Endowed with knowledge of the underlying policy process, private agents act as Bayesian updaters to infer policy regime from realizations of past policy variables. The true economy generates some objects of interest: (1) nonlinear dynamics with agents updating their beliefs about regime; (2) linear dynamics conditional on a given regime; (3) large-sample linear dynamics that average across regimes.

A policy advisor who seeks to inform policymakers of the likely effects of alternative policy actions performs positive policy evaluation. We assume that due to technological limitations the policy advisor cannot model the true nonlinear economy, so object (1) is unattainable. Instead, we arm the advisor with a (misspecified) linear model and explore conditions under which linear projections conditional on hypothetical policy interventions will closely approximate the truth. Although attainable, object (3) holds little interest to the advisor, as it embodies a linear combination of private decision rules, a combination that is systematically wrong.

\footnotetext{
* We thank Ralph Bryant, Peter Clark, Tom Cooley, Jon Faust, John Geweke, Ross Levine, Adrian Pagan, Peter Pedroni, Tom Sargent, Anders Vredin, Mike Woodford, and especially David Gordon, Chris Sims, and Dan Waggoner for helpful suggestions. The views expressed herein are not necessarily those of the Federal Reserve Bank of Atlanta or the Federal Reserve System.
} 
To estimate a linear model, the advisor selects a sample period when policy has operated in a single regime. Conditioning on that regime, the advisor reports projections conditional on hypothetical policy interventions and two additional useful pieces of information: (a) the class of interventions that make the current regime tenuous; (b) the class of interventions that are consistent with the prevailing regime. Policymakers know that predictions of policies drawn from class (a) may be unreliable, while the projections of policies from class (b) are likely to be good approximations to the truth.

The theoretical model decomposes the total impact of a policy intervention into a direct effect and an expectations-formation effect. Direct effects are the usual policy impacts that arise when regime is fixed. Direct effects include any intra-regime changes in expectations of policy that the intervention generates, but do not include any impacts due to changes in agents' beliefs about regime and therefore do not shift decision rules. Expectations-formation effects arise when the policy intervention induces agents to update their beliefs about policy. These inter-regime changes shift both the public's expectations-formation rules and their decision rules in the systematic way that Lucas encouraged the profession to model.

We study interventions that vary in magnitudes and dynamic pattern, and report a statistic that indicates whether direct effects are improbably large relative to their normal historical variation. An intervention is modest when this statistic is close to its mean. We show that - contrary to the priors of many economists, modest policy interventions may have substantial impacts without generating important expectations-formation effects, which undermine the reliability of linear projections;

- a small but persistent intervention is more likely to destabilize a linear model than is a large but fleeting intervention - a refinement of a point that Lucas (1976) emphasizes.

We apply the approach to policy analysis developed in the theory to an empirical model fit to post-war U.S. data. The model projects the macro economy conditional on hypothetical interventions designed to address questions Federal Reserve officials may have asked. In the identified vector autoregression (VAR) we estimate, the conditional projections reflect only direct effects of policy. For every intervention, we report the modesty statistic to determine whether the direct effects are large relative to their historical variation. Whenever a policy intervention generates unusually large direct effects - which may or may not trigger substantive 
shifts in beliefs - we label it immodest and we infer that the VAR is likely to perform badly by missing important expectations-formation effects.

We display several examples from the U.S. experience. In some cases the modesty statistic calls for healthy skepticism about the VAR. In other cases one can feel confident that the intervention, if implemented, would not generate substantial expectations-formation effects. Many interventions that might arise in routine Federal Open Market Committee (FOMC) discussions are modest, suggesting that an identified VAR would be a reliable forecasting tool. The direct effects of modest interventions can shift the projected paths and probability distributions of macro variables in ways that matter to policy makers.

\section{Contacts with Literature}

This work makes several points of contact with existing literature. To some readers, the environment described in the introduction may resemble the one in which the Federal Reserve operates. With no mechanism binding the Fed's choices in the future, a skeptical public bases its beliefs more on the actions of the FOMC than on the statements of Fed officials. This skepticism makes the history of actions matter. Although many observers credit the decline of inflation in the 1980s to a shift in monetary policy behavior, even the most sanguine proponents of recent Fed successes cannot exclude the possibility of a return to inflationary policies, as in Sargent's (1999) analysis of American inflation.

Despite the description's ring of relevance, macro policy analyses typically do not use this environment. Standard analyses instead mimic the examples Lucas (1976) used to illustrate his critique of econometric policy evaluation. Rather than an on-going process, in Lucas's thought experiment policy choice is once-and-for-all.

Several authors have pointed out a problem with posing policy as making once-and-for-all choices: it is logically inconsistent [e.g., Cooley, LeRoy and Raymon (1982,1984), Sargent (1984), and Sims $(1982,1987,1998)]$. Treating regime changes as surprises that will never occur again ascribes to the public beliefs about policy that are inconsistent with actual behavior - the government takes actions that the public thought were impossible. Cooley, LeRoy and Raymon (1982) resolve the inconsistency by proposing the general principle for policy analysis that “... any entity which changes over time in a way that is not completely predictable should be modeled as a sequence of random variables." In applying this principle, Cooley, LeRoy, and 
Raymon lay a probability distribution over all possible rules and define a policy intervention as a sequence of realizations of policy variables, rather than a permanently new rule. Agents' decision rules then incorporate the belief that it is always possible to return to the good (bad) old days of policymaking.

Viewing policy as evolving stochastically leads to an interpretation of the Lucas critique that expands on Sims's (1998) observation that the critique can be interpreted as pointing toward a potentially important source of nonlinearity. In the face of sustained dynamic patterns of change in policy variables, agents may grow to believe that policy behavior has shifted, and respond by adjusting their expectations and decision rules accordingly. This interpretation does not diminish the potential force of Lucas's critique; instead it provides a framework for isolating and quantifying the effects of the behavior that Lucas emphasizes.

\section{A Theoretical Framework for Policy Analysis}

In the following theoretical framework a modest intervention is defined precisely. Examples show cases where an intervention generates large direct effects without inducing the shifts in agents' beliefs about regime that generate substantial expectations-formation effects. Examples also display interventions whose direct and expectations-formation effects are both large.

Policy analysis in the theory is couched in terms of forecasts conditional on interventions. This corresponds to procedures the Federal Reserve employs and to the empirical exercises section 5 implements.

\subsection{The Model}

The model extends Cochrane's (1998) setup to allow policy behavior to switch randomly between two regimes. Price-setting behavior is based on the costly price adjustment framework of Rotemberg $(1982,1996)$, and generates predictions that are consistent with models that introduce nominal rigidities through other means. ${ }^{1}$ Cochrane combines a simple aggregate demand specification with the dynamic price-setting behavior. Costly price adjustment allows expected monetary policy to have both price and output effects.

Pricing behavior involves inertial and forward-looking components. Costs of adjusting prices are parameterized by $\alpha \in[0,1]$, which determines the degree of stickiness. A

${ }^{1}$ For example, Calvo (1983) faces firms with a constant probability of adjusting their prices. 
representative monopolistically competitive firm chooses the price sequence $\left\{p_{t}\right\}$ to maximize profits discounted at rate $\beta \in(0,1)$, leading to the price-adjustment equation:

$$
p_{t}=\alpha p_{t-1}+(1-\alpha)(1-\alpha \beta) E_{t-1} \sum_{j=0}^{\infty}(\alpha \beta)^{j} m_{t+j}, 2
$$

where $m$ is the nominal money stock and all variables are in logarithms. A simple money demand expression links output and money: $y_{t}=m_{t}-p_{t}$.

Combining (1) with the demand for money implies the expression for equilibrium output

$$
y_{t}=\left[m_{t}-\frac{1-\alpha}{1-\alpha L} E_{t-1} \frac{1-\alpha \beta}{1-\alpha \beta L^{-1}} m_{t}\right] .
$$

As Cochrane observes, driving adjustment costs to zero $(\alpha \rightarrow 0)$ reduces the model to Lucas's $(1972,1973)$ environment in which only unanticipated money affects output: $y_{t}=m_{t}-E_{t-1} m_{t}$. As $\alpha \rightarrow 1$, adjustment costs become infinite and the distinction between anticipated and unanticipated policy disappears: $y_{t}=m_{t}-p$, where $p$ is the constant price level.

To complete the model we posit a process for setting the money supply that randomly switches between two policy regimes. Let $g_{t}$ be the growth rate of the nominal money supply between $t-1$ and $t$ :

$$
m_{t}=g_{t}+m_{t-1}
$$

given some initial money stock, $m_{0}>0$. Denoting the regime at $t$ by $R_{t}$, the policy rule is

$$
g_{t}=\mu\left(R_{t}\right)+\rho\left(R_{t}\right) g_{t-1}+\sigma\left(R_{t}\right) \varepsilon_{P_{t}}, \quad \varepsilon_{P t} \sim N(0,1), \quad g_{0}>0 .
$$

The specification allows for the possibility that a shift in policy regime changes the dynamics, the mean, and the variance of money growth. ${ }^{3} \varepsilon_{P}$ is an intra-regime exogenous shift in policy.

${ }^{2}$ This expression derives from a price-setting firm that chooses $p_{t}$ based on information at time $t-1$ to maximize

$$
-.5 E \sum_{t} \beta^{t}\left[(1-\alpha)(1-\alpha \beta)\left(p_{t}-m_{t}\right)^{2}+\alpha\left(p_{t}-p_{t-1}\right)^{2}\right] .
$$

In this expression, $p_{t}=m_{t}$ is the equilibrium price level in the absence of adjustment costs. The first-order condition may be solved for the price level to obtain (1) in the text.

${ }^{3}$ Cooley, LeRoy and Raymon (1982) and Andolfatto and Gomme (2003) consider less general regime-switching specifications in general equilibrium models. 
Label the two policy regimes $R^{1}$ and $R^{2}$. Regime switches obey a Markov chain with transition probabilities

$$
P=\left[\begin{array}{cc}
P\left[R_{t}=R^{1} \mid R_{t-1}=R^{1}\right] & P\left[R_{t}=R^{1} \mid R_{t-1}=R^{2}\right] \\
P\left[R_{t}=R^{2} \mid R_{t-1}=R^{1}\right] & P\left[R_{t}=R^{2} \mid R_{t-1}=R^{2}\right]
\end{array}\right]=\left[\begin{array}{cc}
p_{11} & 1-p_{22} \\
1-p_{11} & p_{22}
\end{array}\right],
$$

and associated policy parameters

$$
\left(\mu\left(R_{t}\right), \rho\left(R_{t}\right), \sigma\left(R_{t}\right)\right)=\left\{\begin{array}{l}
\left(\mu_{1}, \rho_{1}, \sigma_{1}^{2}\right) \text { if } R_{t}=R^{1} \\
\left(\mu_{2}, \rho_{2}, \sigma_{2}^{2}\right) \text { if } R_{t}=R^{2}
\end{array} .\right.
$$

The policy process is completely defined by equations (3)-(6) and values for the vector of policy parameters $\Pi \equiv\left(\mu_{1}, \mu_{2}, \rho_{1}, \rho_{2}, \sigma_{1}^{2}, \sigma_{2}^{2}, p_{11}, p_{22}\right)$. A realization of policy at $t$ is the pair $\left(g_{t}, R_{t}\right)$. Let $\Omega_{t}=\left\{p\left(R_{0}\right), m_{0}, g_{0}, g_{1}, \cdots, g_{t}\right\}$ where $p\left(R_{0}\right)$ is agents' prior belief about regime at the time 0 . Agents' decisions at $t$ are based on information contained in the set $\Omega_{t-1}$, along with $\Pi$ and their beliefs about regime, $P\left(R_{t-1}=R^{s} \mid \Omega_{t-1}\right)$, for $s=1,2$. We assume agents observe the history of money growth realizations, but none of the realizations of regime.

\subsection{Direct and Expectations-Formation Effects}

When regime is fixed, the model is linear and has a vector autoregressive representation. ${ }^{4}$ The $K$-period forecast from the VAR under Regime 1 , given information at $T$, is

$$
x_{T+K}=\sum_{s=0}^{K-1} C_{s} \varepsilon_{T+K-s}+E\left(x_{T+K} \mid \Omega_{T}, R_{t}=R^{1}\right),
$$

where $x_{t}=\left(p_{t}, y_{t}, m_{t}\right)^{\prime}$ is a vector of variables from the model, $C_{s}$ is the impulse response matrix at horizon $s, E\left(x_{T+K} \mid \Omega_{T}, R_{t}=R^{1}\right)$ is the projection conditional on information in $\Omega_{T}$ and on policy being in Regime 1 for $t=T+1, \ldots, T+K$, and $\varepsilon_{T+K-s}=\left(0,0, \varepsilon_{P, T+K-s}\right)^{\prime}$. Direct effects and expectations-formation effects from a policy intervention are computed from forecasts from fixed-regime and switching-regime models conditional on a given intervention. The forecasts

\footnotetext{
${ }^{4}$ Under a fixed regime the model's price equation is:

$$
p_{t}=\alpha p_{t-1}+\frac{1-\alpha}{1-\alpha \beta \rho}\left[(1+\rho(1-\alpha \beta)) m_{t-1}-\rho m_{t-2}+\frac{\mu}{1-\alpha \beta}\right] .
$$
}


are reported relative to a baseline forecast that is conditional on no intervention, denoted by $E\left(x_{T+K} \mid \Omega_{T}, R_{t}=R^{1}\right)$ in (7).

Let $I_{T}$ be a hypothetical intervention at time $T$, specified as a $K$-period sequence of exogenous policy shifts, $I_{T}=\left\{\tilde{\varepsilon}_{P, T+1}, \ldots, \tilde{\varepsilon}_{P, T+K}\right\}$. Although the policy advisor chooses $I_{T}$, private agents treat it as random. Construct a forecast of $\left\{x_{T+K}\right\}$ conditional on $I_{T}$, denoted by $E\left(x_{T+K} \mid I_{T}, \Omega_{T}, R_{t}=R^{1}\right)$. Direct effects of $I_{T}$ relative to the no-intervention forecast are

$$
\text { Direct Effects } \equiv \eta_{P, T+K}=\sum_{s=0}^{K-1} C_{s} \tilde{\varepsilon}_{P, T+K-s}=E\left(x_{T+K} \mid I_{T}, \Omega_{T}, R_{t}=R^{1}\right)-E\left(x_{T+K} \mid \Omega_{T}, R_{t}=R^{1}\right) .
$$

When regime may change, the economy is nonlinear and the VAR form in (7) no longer holds. Now an intervention may trigger changes in agents' beliefs about policy regime, which affects agents' expectations of future policy and their optimal choices. Total effects of policy combine direct effects with expectations-formation effects, which changes in beliefs about regime induce. Total effects relative to the no-intervention projection in the linear model are:

$$
\text { Total Effects } \equiv E\left(x_{T+K} \mid I_{T}, \Omega_{T}\right)-E\left(x_{T+K} \mid \Omega_{T}, R_{t}=R^{1}\right),
$$

where the same intervention, $I_{T}$, is conditioned on in (8) and (9). Because regime can shift, total effects depend on agents' beliefs about regime at the time of the intervention.

We compute direct effects and total effects relative to the same baseline in order to isolate expectations-formation effects, defined as the difference between (9) and (8):

$$
\text { Expectations-Formation Effects } \equiv \text { Total Effects - Direct Effects. }
$$

Expectations-formation effects arise from the changes in behavior that lie at the heart of Lucas's (1976) critique. A natural way to judge whether the Lucas critique is important is to check if expectations-formation effects are small. If those effects are small, then forecasts from a model that assumes policy regime is fixed will be reasonably accurate.

If, in contrast, expectations-formation effects are large relative to direct effects, then the fixed-regime model's predictions will be systematically wrong. The linear approximation is likely to breakdown as the nonlinearity triggered by expectations-formation effects is relatively important. This is the situation on which Lucas focuses. 


\subsection{Simulating the Model}

The theory offers a laboratory for finding examples of interventions where the Lucas critique bites. By separating direct and expectations-formation effects, the theory implies a natural measure of whether a particular intervention is modest (section 3.4.1).

Of course any inferences about whether the Lucas critique bites for a given intervention depend on the model's parameterization. We focus on two different sets of parameters. In the first set the policy regimes are far apart so shifts in beliefs about regime can generate quantitatively important expectations-formation effects under certain conditions (section 3.4.2). The second set makes the two regimes much closer and expectations-formation effects tend to be small for many interventions (section 3.4.3). We focus on two kinds of interventions that differ in their persistence and their timing. A 4-year forecast horizon is chosen to coincide with a typical horizon the Federal Reserve considers.

With policy regime a hidden state variable, agents behave as Bayesian updaters and use the observed information set to infer the probability of being in each of the two regimes. Suppose agents have initial beliefs about $R_{t-1}$ denoted by $P\left(R_{t-1}=R^{s} \mid \Omega_{t-1}\right)$ for $s=1,2$. At time $t+h$, when $\Omega_{t+h}$ is available, agents compute $P\left(R_{t+h} \mid \Omega_{t+h}\right)$ recursively as Hamilton (1994) outlines.

To simulate the model we specify values for the private parameters, $(\alpha, \beta)$, and the policy parameter vector, П. Taking the period of the model to be monthly, as in the identified VAR estimated in section 4 , we set $\beta=.99674$, which yields an average annual real interest rate of 4.0 percent. To make expectations-formation effects potentially large, we set $\alpha=.9$, implying costly price adjustment and important impacts of expected policy on output. ${ }^{5}$ Transition probabilities are chosen as $p_{11}=.99722, p_{22}=.99167$, so that in a monthly model Regime 1 (low money growth) lasts 30 years on average, and Regime 2 (low money growth) lasts 10 years.

\subsubsection{A Statistic for Modest Interventions}

For a given intervention, the distribution of direct effects may be obtained from the sequence of forecast errors computed in (8). The statistic $\eta_{P, T+K}^{*}$, which scale $\eta_{P, T+K}$ by the variance

\footnotetext{
${ }^{5}$ When $\alpha=0$ both direct and expectations-formation effects on output are small because only unanticipated money growth matters for output. Expectations-formation effects on prices are also small because only the one-step forecast of money enters the pricing function.
} 
$\sum_{s=0}^{K-1} C_{s}^{2}$, has a standard normal distribution. Total effects and expectations-formation effects are also measured relative to the standard errors of direct effects for comparison.

Definition: An intervention is modest if its direct effects are small. More precisely, an intervention is modest over a specified forecast horizon, $K$, and for variable $i$, if

$$
\left|e_{i} \eta_{P T+K}^{*}\right|<2 \text {, }
$$

where 2 represents two standard deviations and $e_{i}$ is a row vector of zeros with unity in the $i^{\text {th }}$ column. ${ }^{6} \eta^{*}$ reports how unusual a conditional forecast is relative to the typical size of the direct effects, as measured in units of standard deviations of direct effects. When an intervention violates (11), the forecasted paths are unlikely to be due to direct effects alone, so expectationsformation effects may be important.

\subsubsection{Policy Regimes with Extreme Differences}

Logical points linking hypothetical interventions to their direct and expectations-formation effects are most clearly made by assuming large differences in policy behavior across regimes. We choose rules that imply average annual money growth rates of 3.04 percent and 13.08 percent, slightly different serial correlation patterns, and the same variance of the policy shock across regimes. The parameters are summarized in Table 1.

We begin with the special case of the one-period intervention described by $I_{T}=\{1,0, \ldots, 0\}$. By conditioning on the counterfactual that Regime 1 prevails now and in the future, the exercise corresponds to conventional impulse response analysis. Figure 1 reports percent deviations from no-intervention forecasts of money, prices, and output. The intra-regime monetary expansion generates a hump-shaped increase in output that peaks at over 0.3 percent after seven months, and smooth increases in both prices and the money stock that converge to permanently higher (and equal) levels. Monetary surprises have their biggest impacts on output and inflation within a year. The hump-shaped path of output and the smooth, gradual response of prices resemble the policy impacts found in the empirical model of section 4, though the timing and magnitudes differ. Direct effects of alternative policy interventions are functions of the impulse responses in Figure 1. 
We turn now to an intervention that is sustained but relatively small (less than one standard deviation) in each of 48 months: $I_{T}=\{2 / 3,2 / 3, \ldots, 2 / 3\} .^{7}$ Figure 2 records information about the intervention in three panels. The first panel records the percentage deviation from the nointervention forecast of the money stock and the posterior probability that policy is in Regime 1 . Direct and expectations-formation effects on prices and output appear in the next two panels, expressed as percentage changes from their no-intervention paths. These are cumulative impacts: in month $j$ the dynamic impacts of all the interventions from $T+1$ to $T+j$ appear. The intervention persistently puts relative likelihood weight on Regime 2, smoothly shifting agents' beliefs away from Regime 1. As beliefs evolve, expectations-formation effects grow in importance. Because price adjustment is costly $(\alpha=.9)$, the expectations-formation effects show up more strongly in output than in prices. Direct effects and expectations-formation effects on prices are reinforcing, though they have opposite influences on output. At 48 months the total effects on output are close to zero: the cumulative expectations-formation effects reduce output by nearly 4 percent, offsetting the increase due to direct effects.

Table 2 summarizes these impacts and reports the modesty statistic for this intervention in the $48^{\text {th }}$ month (Specification A under extreme case). Absolute values of $\eta^{*}$ larger than 2 imply the intervention is not modest. The table also reports expectations-formation effects relative to direct effects. Although expectations-formation effects are large relative to direct effects only in the case of output, the modesty statistic implies that the resulting paths of both output and prices are unlikely to arise in the absence of substantial expectations-formation effects. This makes clear the sense in which our statistic is necessary for signaling a linear model will breakdown.

To highlight the role of the dynamic pattern of intervention, we consider an intervention that is large but short-lived: $I_{T}=\{8,8,8,8,0, \ldots, 0\}$. The cumulative size of the intervention is the same as in Specification A. This intervention produces extremely rapid money growth for the first four months. The money growth rates caused by these huge shocks are so unlikely to occur

\footnotetext{
6 The statistic is in the spirit of Doan, Litterman, and Sims's (1984) "implausibility index," though theirs applies only to reduced-form forecasts.

${ }^{7}$ The linear model in Regime 1 requires a sequence of $\tilde{\varepsilon}_{P}$ 's on the order of 1.0 to mimic policy behavior in Regime 2 with zero intra-regime shocks. Although shocks of $2 / 3$ do not put policy realizations at the center of Regime 2 , they are sufficient to change agents' beliefs.

Unless otherwise noted, initial beliefs about regime were set at $P\left(R_{T}=R^{1}\right)=.98$.
} 
under Regime 1 that agents quickly become nearly certain policy switched to Regime 2 (Figure 3). With a lack of persistence in the intervention, as soon as the shocks disappear agents revert to believing Regime 1 prevails. The direct and expectations-formation effects on output are shrunken mirror images of each other and closely resemble the shape of the impulse response function in Figure 1. Over very short horizons, direct effects and expectations-formation effects on the price level are nearly identical, but direct effects soon become dominant at longer horizons. The cumulative expectations-formation effects at 48 months are very small on both variables. This outcome is confirmed by the modesty statistic for output, but the statistic suggests the price path is unlikely to emerge from direct effects alone (Table 2, Specification B). This is a situation where the horizon of concern plays an important role in determining the usefulness of the linear model. Policy makers concerned with very short horizons may choose to down weight the model's influence. Most monetary policy makers, however, focus on horizons of two or more years. For them the message of the simulation is that a short-lived interventioneven a large intervention - is likely to generate only small expectations-formation effects over horizons relevant to policy. At those horizons the predictions of a linear econometric model are likely to be reliable.

Table 2 also reports how sensitive results are to the total size of the intervention, to the duration of regime, and to agents' initial beliefs about regime. Specification $\mathrm{C}$ cuts in half the magnitude of the intervention in Specification A, but maintains the sustained nature of the intervention. In this case, the expectations-formation effects on both output and prices are small and the modesty statistic raises no warning flags for output, though the statistic slightly exceeds 2 for prices. Even a sustained intervention may not undermine the accuracy of a linear approximation if the intervention is sufficiently small.

Regime duration influences agents' beliefs. Specification D reproduces Specification A but reduces the duration of Regime 2 from 10 years to 1 year. Making Regime 2 ephemeral greatly increases the likelihood that Regime 1 produced the realized path of money growth; agents' posterior probability of Regime 1 falls only to 0.38 (as compared to 0.04 in Specification A). As consequence, expectations-formation effects on output, which were substantial when Regime 2 was longer lived, are now small. Because the direct effects of the intervention on output and prices are identical to Specification A, the modesty statistic is unchanged. 
It is possible for the modesty statistic $\eta^{*}$ to mislead. In special circumstances an intervention may produce large enough expectations-formation effects to cause trouble for the linear model, yet generate direct effects small enough for the intervention to be deemed modest. Suppose that for some reason agents hold strong beliefs that policy is in Regime 2 at date $T$ (e.g., $\left.P\left(R_{T}=R^{1}\right)=.02\right)$. The policy advisor considers a very small 48-month intervention, say, $I_{T}=\{.2, .2, \ldots, .2\}$, that is couched as a sequence of $\tilde{\varepsilon}_{P}$ 's in Regime 1 . This situation is labeled $\mathrm{E}$ in Table 2. The advisor predicts this intervention will generate small direct effects, with $\eta^{*}$ 's well below 1.5 for prices and output. Because agents initially believe policy is in Regime 2, the relatively small money growth realizations that the intervention generates begin slowly to shift their beliefs back in favor of Regime 1; even after 4 years they continue to place more probability on Regime 2. Shifting beliefs produce expectations-formation effects for output that are large relative to the standard error of the direct effects (about -2.0$)^{8}{ }^{8}$

Although we think these circumstances are atypical, there is a way to detect if they are likely in practice. First, it's important to understand how agents might come to believe Regime 2 prevails when the advisor thinks Regime 1 is relevant. Suppose that in the period before date $T$, policy implemented the intervention in Specification A. At $T-1$ agents place very high probability on Regime 2 (Figure 2), yet the advisor regards the intervention as a deviation within Regime 1 . This places the economy at $T$ in a situation where a very small but persistent intervention on Regime 1 that produces tiny direct effects could lead to significant expectationsformation effects.

This situation can be detected in practice by an ex-post analysis that extracts from the linear model the sequence of realized $\hat{\varepsilon}_{P}$ 's up to the forecast date $T$. If those realizations do not display a pattern of intervention that would shift private beliefs substantially toward Regime 2 , the troublesome circumstances are not likely. ${ }^{9}$ In the empirical model of section 5.4 we perform this ex-post analysis.

${ }^{8}$ If, in contrast, initial beliefs were $P\left(R_{T}=R^{1}\right)=.98$, expectations-formation effects on output are nearly 7 times smaller.

${ }^{9}$ Large expectations-formation effects with small direct effects might emerge from credible policy regime announcements. Analysis of announcements is beyond the scope of this paper. 
Extreme differences in regimes can translate changes in beliefs about regime into substantial expectations-formation effects. When differences in regimes are less pronounced, shifts in beliefs need not generate important expectations-formation effects. Minor expectationsformation effects can be generated by interventions that produce quantitatively large direct effects when policy regimes are close.

\subsubsection{Policy Regimes with Less Extreme Differences}

This section reports sensitivity analysis by considering regimes that are closer than those in section 3.4.2. Table 1 reports parameters loosely calibrated to U.S. data on monthly M2 growth rates since 1959. ${ }^{10}$ Those parameters, obtained by breaking the sample into two "regimes," imply average annual money growth rates of 6.4 percent in Regime 1 and 9.4 percent in Regime 2 ; the lower money growth regime is associated with somewhat greater persistence and lower variance of the shock.

When regimes exhibit less extreme differences the same interventions considered above yield dramatically different results. Consider again the sustained interventions of $2 / 3$ of a standard deviation each period, Specification A. The intervention generates substantial direct effects, raising the price level 19 percent and output 4 percent above their no-intervention levels. Agents' beliefs about regime do not move from their initial belief that Regime 1 is very likely. The reason is that the conditional likelihood under Regime 2 is more dispersed than under Regime $1\left(\sigma_{2}>\sigma_{1}\right)$, so the interventions have to be larger to make Regime 2 more likely. Reinforcing the influence of the relative variances of shocks in the two regimes is that money growth is less persistent in Regime $2\left(\rho_{1}>\rho_{2}\right)$. If realized money growth exceeds the unconditional mean in Regime 2, agents would expect more rapid mean reversion in Regime 2 than is consistent with the persistent intervention. This makes the Regime 2's conditional likelihood value less than Regime 1's. Unchanged beliefs lead to very small expectationsformation effects in spite of the substantial direct effects the intervention produces. The modesty statistic indicates this is not a modest intervention, with scaled direct effects on a par with those under the extreme specification of regime differences (Table 2 under less extreme case). This example underscores the conservative nature of our statistic: scaled expectations-formation

\footnotetext{
${ }^{10}$ Maximum likelihood estimates from a Hamilton (1989) regime-switching model would not yield qualitatively different inferences about the distance between the two regimes.
} 
effects are tiny for both the price level and output, suggesting a linear approximation would perform well.

The large, but brief, intervention in Specification B in Table 2 generates rapid changes in beliefs about regime, but miniscule expectations-formation effects because the two regimes are very close. When the large interventions end, agents return to believing Regime 1 prevails. Expectations-formation effects on both prices and output are very small, even in the short run, despite large direct effects that raise output by more than 10 percent in the short run. By 48 months, the cumulative direct effects on prices exceed those under Specification A, but the direct effects on output have died out. Table 2 indicates that this is a modest intervention for both output and prices.

Small differences in regimes reduce the chance that the modesty statistic will mislead. We repeat the Specification E exercise. Table 2 reports that when regimes are close the small direct effects are no longer associated with large expectations-formation effects. Now the scaled expectations-formation effects are 0.03 for prices and -0.10 for output. These arise despite rapid and complete reversal in beliefs from Regime 2 to Regime 1. Changes in beliefs generate large expectations-formation effects only when there are significant differences across policy regimes.

In the empirical analysis below, the interventions we consider that correspond to actual Federal Reserve behavior are smaller and briefer than those studies in the theoretical examples. The empirical interventions are modest according to our statistic, yet they generate economically meaningful direct effects.

\section{The Econometric Model}

This section specifies and estimates a small structural model of American monetary policy behavior. The section reports the model's impulse response functions, which are the direct effects of a particular policy intervention, and discusses the model's fit, stability, and suitability for policy analysis.

\subsection{The Model}

Actual policy behavior is a complicated function of a high-dimensional vector of variables. Policymakers choose $R_{t}$, the vector of policy choices at date $t$, as a function of their information set, $\Omega_{t}$. Actual policy behavior is a function $g$ such that 


$$
R_{t}=g\left(\Omega_{t}\right)
$$

(12) describes historical policy behavior.

We assume that private agents are not privy to the details of the policymakers' decision problems, including the policymakers' incentives and constraints. That is, they observe the information set $S_{t} \subset \Omega_{t}$. Agents perceive that policy is composed of a regular response to the state of the economy that they observe at time $t, S_{t}$, and a random part, $\varepsilon_{P t}$. The econometric model of policy is:

$$
R_{t}=f\left(S_{t}\right)+\varepsilon_{P t} .
$$

We take $f$ to be linear. $\varepsilon_{P t}$ is exogenous to the econometric model. A policy regime is a choice of $g$, which implies an $f$ and a stochastic process for $\varepsilon_{P} \cdot{ }^{11}$

The econometric model embeds the policy behavior in (13) in a system of equations. If $y_{t}$ is an $(m \times 1)$ vector of time series, the structural form is

$$
\sum_{s=0}^{p} A_{s} y_{t-s}=\varepsilon_{t},
$$

where $\varepsilon_{t}$ is a vector of i.i.d. structural disturbances that are exogenous to the model. Those disturbances hit both nonpolicy and policy sectors of the economy, so

$$
\varepsilon_{t}=\left[\begin{array}{l}
\varepsilon_{N t} \\
\varepsilon_{P t}
\end{array}\right],
$$

where $\varepsilon_{N t}$ is the vector of nonpolicy disturbances.

The environment developed in section 3 addresses policy questions by using a structure like (14) to project $y$ conditional on hypothesized paths for $\varepsilon_{P}$ [see Marschak (1953)]. We assume $\varepsilon_{P t}$ is a vector of exogenous random variables, uncorrelated with all the nonpolicy exogenous disturbances in the economy. The errors are Gaussian with

$$
E\left(\varepsilon_{t} \varepsilon_{t}^{\prime} \mid y_{t-s}, s>0\right)=I, E\left(\varepsilon_{t} \mid y_{t-s}, s>0\right)=0, \text { all } t .
$$

The $A_{s}$ matrices and the probability distribution of $\varepsilon$ define the model's structure.

${ }^{11}$ It is beyond the scope of this paper to rationalize randomness in policy behavior. See Sims (1987) for one detailed rationale and Leeper, Sims and Zha (1996) for further discussion. 
Assuming the matrix of contemporaneous coefficients, $A_{0}$, is non-singular, there is a representation of $y$ in terms of the impulse responses functions:

$$
y_{t}=\sum_{s=0}^{t-1} C_{s} \varepsilon_{t-s}+E_{0} y_{t} .
$$

Elements of $C_{s}$ report how each variable in $y$ responds over time to the behavioral disturbances in $\varepsilon . E_{0} y_{t}$ is the projection of $y_{t}$ conditional on initial conditions. The reduced form of (14) is

$$
\sum_{s=0}^{p} B_{s} y_{t-s}=u_{t}
$$

with $B_{0}=I$ and the covariance of the reduced-form errors, $u$, is $\Sigma=A_{0}^{-1} A_{0}^{-1^{\prime}}$.

Expressions (14) and (18) imply a linear mapping from the reduced-form errors to the behavioral disturbances:

$$
u_{t}=A_{0}^{-1} \varepsilon_{t} .
$$

Identification of the structural form follows from imposing sufficient restrictions on $A_{0}$ so that there are no more than $m(m-1) / 2$ free parameters in $A_{0}$. Appendix A in Leeper and Zha (2002) describes the Bayesian estimation methods employed.

\subsection{Identification}

We estimate a model that contains six variables and three sectors. The identification scheme follows the general approach in Gordon and Leeper (1994) and Sims and Zha (1998). There are no restrictions on lagged variables. Three goods market variables - real GDP (y), consumer prices $(P)$, and the unemployment rate $(U)$ - compose the production sector, and are the ultimate objectives of monetary policy. We do not model the markets for reserves and a broad monetary aggregate, opting for compactness to treat the $M 2$ money stock as the aggregate and the federal funds rate $\left(R^{f}\right)$ - the monetary policy instrument - as the price that clears the money market. The third sector describes an "information variable" — commodity prices $(C P)$ - that is available at high frequencies and reacts instantaneously to shocks from all sectors of the economy. The data, which the Appendix describes, are monthly from January 1959 to September 1998. Monthly GDP is interpolated from quarterly GDP. All data are logarithmic except for the federal funds rate and the unemployment rate. We estimate the model with 13 lags. 
The identification treats the production sector as predetermined for the rest of the system, reflecting the view that production, pricing, and employment decisions do not respond immediately to shocks from outside the sector. Production sector variables interact only with each other within the period. Money market variables and information variables do not enter this sector, reflecting sluggishness in the goods market due to contracts and advance planning of production. Distinct behavioral equations within the production sector are not identified; instead, the coefficients are arranged in lower triangular form in the order $y, P$, and $U$.

The monetary and information sectors interact simultaneously, with the strongest simultaneity determining the money stock and the federal funds rate. The demand for nominal money balances depends on the short-term nominal interest rate, real income (proxied by real GDP), and the price level. We do not impose short-run homogeneity in prices. Changes in $\varepsilon_{M D}$ reflect exogenous shifts in money demand.

We base the specification of monetary policy behavior in (13) on the information available to the Federal Reserve within the month. During the month, the Federal Reserve sets its interest rate instrument based on current observations on the money stock and commodity prices. ${ }^{12} \mathrm{We}$ set to zero the coefficients on $y, P$, and $U$ in the policy function because within the month the Federal Reserve does not observe these variables directly. ${ }^{13}$ The error term in the monetary policy equation, $\varepsilon_{P}$, represents intra-regime exogenous policy interventions.

An efficient markets assumption guides the specification of the information sector, so commodity prices may respond to all variables immediately. The error term $\varepsilon_{I}$ is the exogenous information disturbance.

\subsection{Parameter Estimates and Direct Effects of Policy}

Table 3 reports the estimated contemporaneous coefficients along with 68 percent equaltailed probability intervals for the behavioral coefficients, estimated over the full sample period. The estimated money demand has reasonable economic interpretations: interest elasticity of demand is negative; output elasticity is positive; price elasticity is small and imprecisely

\footnotetext{
${ }^{12}$ We allow policy to choose not to react strongly to commodity prices by shrinking the prior standard deviation on the coefficient of $C P$ toward the zero prior mean by a factor of .05 .

${ }^{13}$ The Fed has some contemporaneous information about these variables. We experimented with soft zeroes on $P$ and $U$ and found that the more we relaxed the zero restrictions the more likely the identification was to produce nonsensical responses to exogenous monetary policy actions.
} 
estimated. Monetary policy responds strongly to the money stock: disturbances that raise the money stock induce the Fed to increase the federal funds rate. Although the estimates seem to suggest the Fed does not react much to information contained in commodity prices, this interpretation may be misleading. In the policy equation the coefficients on $R^{f}$ and $C P$ are highly correlated (.97), as are the coefficients on $M 2$ and $C P(.72)$; these correlations muddy inferences about individual coefficients.

All but two coefficients are tightly estimated in the information sector. The coefficients on output and $M 2$ are highly correlated with the coefficients on the price level and unemployment, so the separate influences cannot be discerned. The estimates imply a quick reaction of commodity prices to exogenous disturbances from elsewhere in the economy.

We base a probabilistic assessment of the model's overall fit on the shape of the likelihood surface, rather than on tests of whether individual coefficients are different from zero [Sims and Zha (1999)]. Table 3 nonetheless displays the (marginal) .68 probability intervals for individual parameters to show that they are skewed, with most of the probability mass concentrated around the maximum likelihood estimates. Because we care about the equilibrium effects of exogenous policy actions, none of our inferences rest on an individual parameter in $A_{0}$.

Impulse response functions from an estimated VAR correspond to the direct effects we describe in section 3.2 and display in Figure 1 for a fixed-regime version of the theoretical model. Figure 4 displays the $C_{s}$ 's in (17) over 48 months for an exogenous monetary policy contraction. The solid lines are the maximum likelihood estimates of responses and the dashed lines are equal-tailed error bands containing .68 probability.

The contraction raises the funds rate initially and immediately decreases the money stock and commodity prices, both of which continue to decline smoothly over the four-year horizon. After a brief delay, output falls and stays lower, while unemployment rises. Six months after the exogenous action, both output and unemployment are likely to differ from their initial levels. Consumer prices adjust more slowly and are unlikely to be appreciably lower for about a year. After a year prices decline smoothly and remain well below their initial level.

The response of the interest rate to an exogenous policy contraction stands out. In Figure 4 the initial liquidity effect lasts about eight months, but by 18 months the funds rate lies well below its initial level. The lower funds rate then persists. This is the shape of the path of the short-term nominal interest rate following a monetary contraction that Friedman (1968) and 
Cagan (1972) describe as a short-lived liquidity effect followed by income and expected inflation effects. After four years the declines in inflation and the federal funds rate are the same size, as one might anticipate if expected inflation is the dominant source of fluctuations in nominal rates over long periods. The responses in the figures suggest that to lower inflation persistently the Fed should raise the funds rate only briefly. Because lower inflation is ultimately associated with a lower funds rate, the Fed must begin to reduce the rate within about a year, and then keep it lower.

\subsection{Suitability for Policy Analysis}

Any model to be used for policy analysis must be carefully scrutinized. Although our model is overidentified, the restrictions do not invalidate the uses to which we put the model.

Elsewhere we evaluate in-sample and out-of-sample fits, check whether policy and non-policy disturbances are uncorrelated, and examine the stability of responses to exogenous changes in monetary policy [Leeper and Zha (2002)]. An exact small-sample test of the restricted model relative to the reduced-form model using a Bayes factor finds the data weakly favor the restricted model. The model's out-of-sample forecast performance compares favorably to various econometric models, including the Board of Governor's Greenbook forecasts.

A small-sample procedure finds the policy shock is uncorrelated with each of the non-policy shocks and with all five non-policy shocks jointly. With the disturbances uncorrelated, it is reasonable to perform policy evaluation by conditioning on a path of exogenous policy interventions while drawing non-policy disturbances independently.

Finally, the dynamic effects of policy are stable across time. Responses to a policy shock are computed for systems estimated over four sub-periods: 1959:1-1998:9 (entire sample); 1959:11979:9 (pre-Volcker); 1959:1-1982:12 (including non-borrowed reserves targeting); 1959:11998:9 with 1979:10-1982:12 eliminated (excluding non-borrowed reserves targeting). The qualitative responses to exogenous policy interventions are robust across sub-periods. There is some tendency for the responses estimated by eliminating the reserves targeting episode to be slightly weaker and for those estimated only through the end of 1982 to be somewhat stronger. Otherwise, the responses to policy are even quantitatively very similar.

Several implications flow from finding stable parameters. First, over the post-1959 period either monetary policy has resided in a single regime or the various regimes have been too close to be detected statistically. Either implication is consistent with simulation results for parameters 
calibrated to U.S. data (section 3.4.3). Second, there is no evidence that agents' beliefs about regime have changed in quantitatively important ways. Equilibria under changed beliefs can differ markedly from equilibria under a fixed regime, as Specification E in Table 2 demonstrates.

\section{Some Practical Analysis of U.S. Monetary Policy}

This section addresses some questions that Federal Reserve officials may have asked during the 1990s. To do so we compute policy projections under several alternative scenarios tied to actual U.S. policy experience. In each case we check whether the direct effects from the identified VAR are good approximations to the total effects of the contemplated interventions. Our check involves computing an empirical modesty statistic in the same way we computed $\eta^{*}$ for the theory in section 3.4.1.

\subsection{Measuring Policy Interventions}

VAR forecasts capture only the direct effects of interventions. When an intervention generates large direct effects relative to their standard error, we infer the intervention is not modest. The theory in section 3 suggests that immodest interventions may produce important expectations-formation effects that undermine the VAR's forecast accuracy.

In the VAR the $K$-period forecast errors given information at time $T$ arising from the intervention $I_{T}=\left\{\tilde{\varepsilon}_{P, T+1}, \ldots, \tilde{\varepsilon}_{P, T+K}\right\}$ are

$$
\eta_{P}(T, K)=\sum_{s=0}^{K-1} C_{s}(:, i) \tilde{\varepsilon}_{P, T+K-s},
$$

where the monetary policy equation is the $i^{\text {th }}$ equation in the system. As in section 3.4.1, $\eta_{P}(T, K)$ is transformed to the standard normal variables, $\eta_{P}^{*}(T, K)$.

\subsection{An Immodest Intervention}

It is commonplace for central banks to condition forecasts on an unchanged path of the policy instrument. The Bank of England (2000), for example, projects GDP growth and inflation over horizons exceeding two years under the assumption that the official interest rate is 
constant. ${ }^{14}$ As the state of the economy is forecasted to change, however, an unchanged path of the instrument always requires some pattern of intervention.

In September 1990, the federal funds rate stood at 8.20 percent. Suppose the Fed were to hold the rate fixed at 8.20 percent over the next 4 years. Doing this requires a sequence of positive $\tilde{\varepsilon}_{P}$ 's that increase over the forecast horizon, and average $1 \frac{1}{2}$ standard deviations in year 3 and over 2 in the last year. This intervention implies large direct effects:

\begin{tabular}{|c|c|}
\hline Variable & $\eta_{P}^{*}(90: 9,48)$ \\
\hline$y$ & -7.09 \\
\hline$P$ & -4.51 \\
\hline$U$ & 6.69 \\
\hline
\end{tabular}

The intervention is not modest. This situation is similar to Specifications A and C in section 3.4.2 where each month the intervention is small, but the overall intervention is very persistent.

\subsection{Modest Policy Interventions Can Matter}

The efficacy of our forecasting procedure rests on whether conditioning on modest interventions can inform routine policy decisions. It turns out that this class of interventions is rich: it can generate economically meaningful shifts in the distributions of forecasted macro variables and clarify for policymakers the tradeoffs among alternative policies. The analysis also demonstrates that a complete probability model, which quantifies the uncertainties that Brainard (1967) emphasizes, can answer complex joint probability questions about the tradeoffs policymakers face.

We conduct the analysis through the eyes of a policymaker who has information about the economy through September 1990. Minutes of the October 2, 1990 FOMC meeting reveal that the Fed predicted a mild downturn in economic activity followed by a rapid resumption of moderate growth. Political developments in the Middle East, however, generated concerns about future oil prices and created uncertainty about the outlook for inflation. Although the domestic policy directive that emerged from the meeting sought "to maintain the existing degree of pressure on reserve position," several FOMC members dissented. One member favored immediate easing and three members opposed the FOMC's perceived leaning in favor of easing.

\footnotetext{
${ }^{14}$ Central banks frequently interpret a constant instrument path an unchanged stance of policy [Board of Governors of the Federal Reserve System (1999) or Sveriges Riksbank (1999)].
} 
In light of the dissension among FOMC members, we consider two scenarios for the menu of conditional projections to present to policymakers. The first scenario conditions forecasts on the actual path of the federal funds rate from October 1990 to January 1991. An alternative scenario considers tighter policy over those four months.

Figure 5 reports the actual time series, the out-of-sample forecasts conditional on the actual path of the funds rate, and 68 percent probability bands for the forecasts. The actual funds rate was 8.11 percent in October, 7.81 percent in November, 7.31 percent in December, and 6.91 percent in January. With that path of the funds rate, there is substantial probability that inflation will rise above $5 \frac{1}{2}$ or 6 percent through 1993, real growth will fall below 1 percent in 1991, and unemployment will rise to near 7 percent through 1993. Based on the path of the funds rate, it may appear that the Fed was concerned primarily about recession. As it happened, inflation fell to 3 percent by 1992, a recession occurred from July 1990 to March 1991 (according to NBER dating), and unemployment hit 71/2 percent in 1992. Of course, as the model's forecasts confirm, policymakers were unaware in October that the recession began three months earlier.

The FOMC minutes report that some policymakers were concerned about higher inflation. For those members an advisor might prepare forecasts conditional on tighter policy. The forecasts assume an intervention that raises the funds rate by 50 basis points in October (to 8.70 percent) and an additional 25 basis points over the period from November 1990 to January 1991. Ex-ante it appears that tighter policy would reduce the likelihood of higher inflation, but at the cost of raising the probability of negative real growth in 1991 (Figure 6). The point forecasts of output growth and unemployment, conditional on tighter monetary policy, come very close to the actual paths of the variables in 1991 and 1992. In spite of the sharp decline in the projected funds rate in 1991-93, the modest intervention exerts a contractionary influence. ${ }^{15}$

15 To hit the actual path of the funds rate the intervention is $I_{T}=\{0.5,0.1,-0.7,-0.7,0, \ldots, 0\}$ and for tightening it is $I_{T}=\{2.3,1.7,1.0,0.9,0, \ldots, 0\}$. The resulting modesty statistics are

\begin{tabular}{|c|c|c|}
\hline Variable & $\begin{array}{c}\eta_{P}^{*}(90: 9,48) \\
\text { Actual } R^{f}\end{array}$ & $\begin{array}{c}\eta_{P}^{*}(90: 9,48) \\
\text { Tighter Policy }\end{array}$ \\
\hline$y$ & 0.10 & -0.69 \\
\hline$P$ & 0.19 & -1.49 \\
\hline$U$ & -0.02 & 0.04 \\
\hline
\end{tabular}


Debate during the October 1990 FOMC meeting centered on the tradeoffs associated with alternative policy choices. To answer the concerns over economic slowdown and higher inflation, Table 4 reports a variety of joint probabilities involving real GDP growth in 1991 or 1992 or 1993 and inflation in 1992 and 1993, conditional on two alternative policies. "Tighter" policy assumes the same counterfactual policy behavior as in Figure 6, while "Actual $R^{f}$ " adjusts policy to be consistent with Figure 5 .

The probabilities put a sharp point on the tradeoffs Federal Reserve officials perceived they faced. In terms of the marginal probabilities, tighter policy makes it very likely that inflation will remain low in 1992 and 1993 (below 51/2 percent), but it also produces a better than 50 percent chance of a recession in 1991 (negative real GDP growth for the year). More relevant to policymakers is the apparent tradeoff: tighter policy creates a one-third chance of a recession in 1991 or 1992 or 1993 and low inflation in 1992 and 1993.

For an intervention to generate the actual path of the funds rate, the Fed would have to tighten slightly in October and November and then ease in December and January. The column in the table labeled "Actual $R^{f}$ " reports these results. This policy reduces by half the marginal probability of a recession in 1991 while lowering the marginal likelihoods of low inflation in 1992 and 1993. It also greatly reduces the joint probability of a recession in 1991 or 1992 or 1993 and low inflation in 1992 and 1993. Again the tradeoff is clear: the probability of no recession coupled with inflation over $5 \frac{1}{2}$ percent now exceeds 40 percent, compared to 18 percent when policy is tighter.

\subsection{Appraising and Reappraising Policy with Modest Interventions}

Blinder's (1997) description of the appraisal/reappraisal process inherent in routine policymaking is echoed by Kohn (1995, p. 235) who observes that policymakers must "be flexible in revising forecasts and the policy stance in response to new information." This perspective helps to understand the Federal Reserve's "preemptive strike" against inflation in 1994. Our analysis shows that in February the tighter policy looked to be sufficient to offset higher inflation in 1996 and 1997; it was not sufficient by April, once three months of new information arrived. When we reappraise policy in April, a further tightening appears necessary to preempt inflation. The analysis puts empirical flesh on Brainard's (1967) argument for gradualism. 
Figure 7 displays actual data and out-of-sample forecasts made in January under two alternative policy scenarios for February through May. Given that the federal funds rate had been nearly constant at 3 percent over the previous year, a natural baseline maintains this constancy through May. The first intervention, which holds the funds rate constant for 4 months, is $I_{T}=\{-.3,-.2,-.2,-.2,0, \ldots, 0\}$. That policy portends rising inflation over the next several years, exceeding 31/2 percent in 1996 and 1997; but policymakers do not seem to face an unpleasant tradeoff between inflation and real activity. Real GDP is expected to grow at least 3 percent annually from 1995 to 1997 , while the unemployment rate is projected to continue to decline.

Key policy questions at the time were when to raise the rate and how much to raise it. To address these questions we consider an alternative policy of moderate tightening that raises the funds rate along its actual path. Although the actual funds rate rose a full percentage point from January to May, that path requires a relatively small intervention, $I_{T}=\{.5,0, .5,1.1,0, \ldots, 0\} .{ }^{16}$ In January even moderate tightening shifts the projected inflation path down without severely affecting real activity (Figure 7).

The Fed reappraises policy in April with three additional months of news about the economy. Now the baseline of a constant funds rate at 3.75 percent requires the intervention $I_{T}=\{.1,-.3,0, \ldots, 0\}$, and leads policymakers to expect inflation will once again drift toward the $3 \frac{1}{2}$ to 4 percent range in 1996 and 1997 (Figure 8). The outlooks for output and unemployment remain promising, so the Fed still does not face a difficult tradeoff. A somewhat stronger tightening move to match the actual path of the funds rate from May through August pushes the funds rate to 4.47 percent in August. The intervention $I_{T}=\{.8, .4, .1, .8,0, \ldots, 0\}$ achieves this

${ }^{16}$ Both interventions are modest:

\begin{tabular}{|c|c|c|}
\hline Variable & $\begin{array}{c}\eta_{P}^{*}(94: 1,48) \\
\text { Constant } R^{f}\end{array}$ & $\begin{array}{c}\eta_{P}^{*}(94: 1,48) \\
\text { Actual } R^{f}\end{array}$ \\
\hline$y$ & 0.12 & -0.28 \\
\hline$P$ & 0.23 & -0.53 \\
\hline$U$ & -0.02 & 0.07 \\
\hline
\end{tabular}


funds rate path and shifts the mean forecast of inflation down below 3 percent through 1997 without risking recession. ${ }^{17}$

By reappraising their decisions in light of updated forecasts, policymakers move cautiously against inflation. So long as forecasts extend far enough into the future to capture monetary policy's lagged effects, the gradual approach can be successful. This analysis formalizes Blinder's (1997) description of policymaking. It also illustrates why uncertainty about future exogenous disturbances may lead policymakers to move cautiously, as Brainard (1967) instructs.

Some readers might worry that if policy makers use the kind of on-going policy analysis that we describe as a basis for policy decisions, agent's beliefs about regime might shift. The theoretical simulation in section 3.4.2 under Specification E, extreme case, shows that if beliefs have shifted, it is possible for an intervention to generate substantial expectations-formation effects even when its direct effects are small and the modesty statistic provides no warning signal.

We perform an ex-post check of how likely this situation was in January 1994. We estimate the model through January 1994, back out the realized policy disturbances, $\hat{\varepsilon}_{P}$ 's, over the preceding 48 months, and compute an ex-post modesty statistic using the realized disturbances. The statistic yields

\begin{tabular}{|c|c|}
\hline Variable & $\begin{array}{c}\eta_{P}^{*}(90: 2,48) \\
\text { Ex-post }\end{array}$ \\
\hline$y$ & -1.96 \\
\hline$P$ & -1.76 \\
\hline$U$ & 1.94 \\
\hline
\end{tabular}

for forecasts beginning in February 1990 and ending in January 1994. These values for $\eta^{*}$, though still less than two standard deviations, warn that over this period agents' beliefs may have shifted in favor of a new, tighter monetary policy regime.

${ }^{17}$ Again the interventions are modest:

\begin{tabular}{|c|c|c|}
\hline Variable & $\begin{array}{c}\eta_{P}^{*}(94: 4,48) \\
\text { Constant } R^{f}\end{array}$ & $\begin{array}{c}\eta_{P}^{*}(94: 4,48) \\
\text { Actual } R^{f}\end{array}$ \\
\hline$y$ & 0.03 & -0.28 \\
\hline$P$ & 0.05 & -0.54 \\
\hline$U$ & -0.01 & 0.05 \\
\hline
\end{tabular}


Although this ex-post statistic raises a warning flag, we judge that the conditional projections of interventions in January and April 1994 are reliable. The judgment call is based on three considerations. First, a change in beliefs about regime is necessary but not sufficient for undermining the reliability of the linear approximation. As the theoretical simulations in section 3.4.3 show, if regimes are relatively close, the resulting expectations-formation effects tend to be small. Second, as Leeper and Zha (2002) show, the responses to policy disturbances are extremely stable across estimation periods ending in September 1990, January 1994, and April 1994. If changes in beliefs generated quantitatively important expectations-formation effects, one would expect to observe greater instability in the response functions. Finally, the large $\eta^{*}$ 's arise from only a few positive interventions larger than one standard deviation, but there is no clear sign pattern in the interventions that might systematically shift beliefs as they do in the theoretical simulations. These observations underscore the bias that can arise from applying the modesty statistic without factoring in the dynamic patterns an intervention implies.

\section{Concluding Remarks}

This paper offers a framework for the analysis of modest policy interventions. The framework embeds rational expectations and respects the Lucas critique. In an environment where policy can switch regime and agents are continually learning about policy regime, the effects of a policy intervention consist of direct effects (which hold agents' beliefs about policy regime fixed) and expectations-formation effects (which reflect changes in expectations functions induced by changes in beliefs). When expectations-formation effects are important, agents' decision rules shift in precisely the way Lucas emphasizes. This behavior introduces a type of nonlinearity that can undermine the forecast accuracy of a linear econometric model. A modest policy intervention is a change in policy consistent with historical variation in policy under the prevailing regime. Theoretical simulations show that an intervention can generate large direct effects without producing important expectations-formation effects.

The paper applies the theoretical framework to an identified VAR model of U.S. monetary policy. That model finds to be modest a rich class of interventions that the Federal Reserve routinely considers. The empirical model predicts that modest interventions can matter: they may shift the projected paths and probability distributions of macro variables in economically 
meaningful ways. The empirical findings imply that accurately identified linear econometric models can reliably predict the impacts of modest policy interventions.

Our methodology has broad applicability. We have stressed its usefulness for the kinds of practical analyses central banks conduct. Closely related techniques are being used to study the behavior of the central bank of Sweden as it implements inflation targeting [Jansson and Vredin (2000)]. Our method also yields insights about the plausibility of answers to counterfactual questions. Hamilton and Herrera (2002) apply the methodology to assess the plausibility of Bernanke, Gertler, and Watson's (1997) counterfactual analysis of the Federal Reserve's response to oil price shocks.

Nothing in the logic of our approach hinges on the use of an identified VAR as the forecasting tool. The distinction between direct effects and expectations-formation effects, the statistic we propose to check if an intervention is modest, and the pitfalls we enunciate all apply with equal force to any linear econometric model of policy.

\section{Data Appendix}

The data, from 1959:1 to 1998:9, are collected from the Bureau of Economic Analysis, the Department of Commerce unless otherwise stated.

Federal Funds Rate: effective rate, monthly average. Source: Board of Governors of the Federal Reserve System (BOG).

M2: M2 money stock, seasonally adjusted, billions of dollars. Source: BOG.

CPI: consumer price index for urban consumers (CPI-U), seasonally adjusted.

GDP: Real GDP, seasonally adjusted, billions of chain 1992 dollars. Monthly real GDP is interpolated using the procedure described in Leeper, Sims and Zha (1996).

Unemployment: civilian unemployment rate (16 and over), seasonally adjusted. Source: Bureau of Labor Statistics.

Commodity Prices: International Monetary Fund's index of world commodity prices. Source: International Financial Statistics. 
Table 1. Parameters for Policy Process in Regime-Switching Model

\begin{tabular}{|c|c|c|c|c|c|c|}
\hline & $\mu_{1}$ & $\mu_{2}$ & $\rho_{1}$ & $\rho_{2}$ & $\sigma_{1}$ & $\sigma_{2}$ \\
\hline $\begin{array}{c}\text { Extreme } \\
\text { Assumptions }\end{array}$ & .0005 & .0007 & .80 & .932 & .0015 & .0015 \\
\hline $\begin{array}{c}\text { Calibration } \\
\text { To U.S. Data }\end{array}$ & .0013 & .003 & .75 & .60 & .0019 & .0024 \\
\hline
\end{tabular}

Calibration to U.S. data achieved by splitting sample into two "regimes" 1959:21971:12/1983:4-2000:07 and 1972:1-1982:12 (excluding 1983:1-1983:3 due to exceptionally high money growth rates) and fitting AR (1) processes to the monthly growth rate of $\mathrm{M} 2$ in each period.

Table 2. Impacts of Policy Interventions at 48-Month Horizon

\begin{tabular}{|c|c|c|c|c|}
\hline \multirow[b]{2}{*}{ Specification } & \multicolumn{2}{|c|}{$\begin{array}{c}\text { Direct Effects } \\
\eta_{P, T+K}^{*} \\
\text { (Standard Deviations) } \\
\end{array}$} & \multicolumn{2}{|c|}{$\begin{array}{c}\text { Expectations- } \\
\text { Formation Effects } \\
\text { (Standard Deviations) }\end{array}$} \\
\hline & $p$ & $y$ & $p$ & $y$ \\
\hline & \multicolumn{4}{|c|}{ Extreme Case } \\
\hline$\overline{\mathrm{A}}$ & 4.53 & 3.45 & 0.86 & $2-3.50$ \\
\hline B & 5.34 & 0.22 & 0.04 & -0.17 \\
\hline $\mathrm{C}$ & 2.07 & 1.61 & 0.16 & -0.63 \\
\hline $\mathrm{D}$ & 4.53 & 3.45 & 0.30 & -1.20 \\
\hline \multirow[t]{2}{*}{$\mathrm{E}$} & 1.30 & 1.04 & 0.48 & -2.01 \\
\hline & \multicolumn{4}{|c|}{$\frac{1}{\text { Less Extreme Case }}$} \\
\hline$\overline{\mathrm{A}}$ & 4.54 & 3.32 & 0.02 & -0.06 \\
\hline B & 5.55 & 0.19 & 0.01 & -0.05 \\
\hline $\mathrm{E}$ & 1.30 & 1.04 & 0.03 & -0.10 \\
\hline \multicolumn{5}{|c|}{$\begin{array}{l}\text { Direct Effects }\left(\eta^{*}\right) \text { and Expectations-Formation Effects scaled by standard errors of } \\
\text { direct effects based on } 5000 \text { draws. } \\
\text { Interventions: } \\
\text { A: } \tilde{\varepsilon}_{P}=.667 \text { in each of } 48 \text { months } \\
\text { B: } \tilde{\varepsilon}_{P}=8.0 \text { for first } 4 \text { months, } \tilde{\varepsilon}=0 \text { for next } 44 \text { months } \\
\text { C: } \tilde{\varepsilon}_{P}=0.333 \text { in each of } 48 \text { months } \\
\left.\text { D: } \tilde{\varepsilon}_{P}=.6667 \text { in each of } 48 \text { months, but } p_{22}=0.9167 \text { (1-year duration of Regime } 2\right) \\
\text { In Specifications A-D, } P\left(R_{T}=R^{1}\right)=.98 . \\
\text { E: } \tilde{\varepsilon}_{P}=0.2 \text { in each of } 48 \text { months, but } P\left(R_{T}=R^{1}\right)=.02 .\end{array}$} \\
\hline
\end{tabular}


Table 3. Maximum Likelihood Estimates of Contemporaneous Coefficients

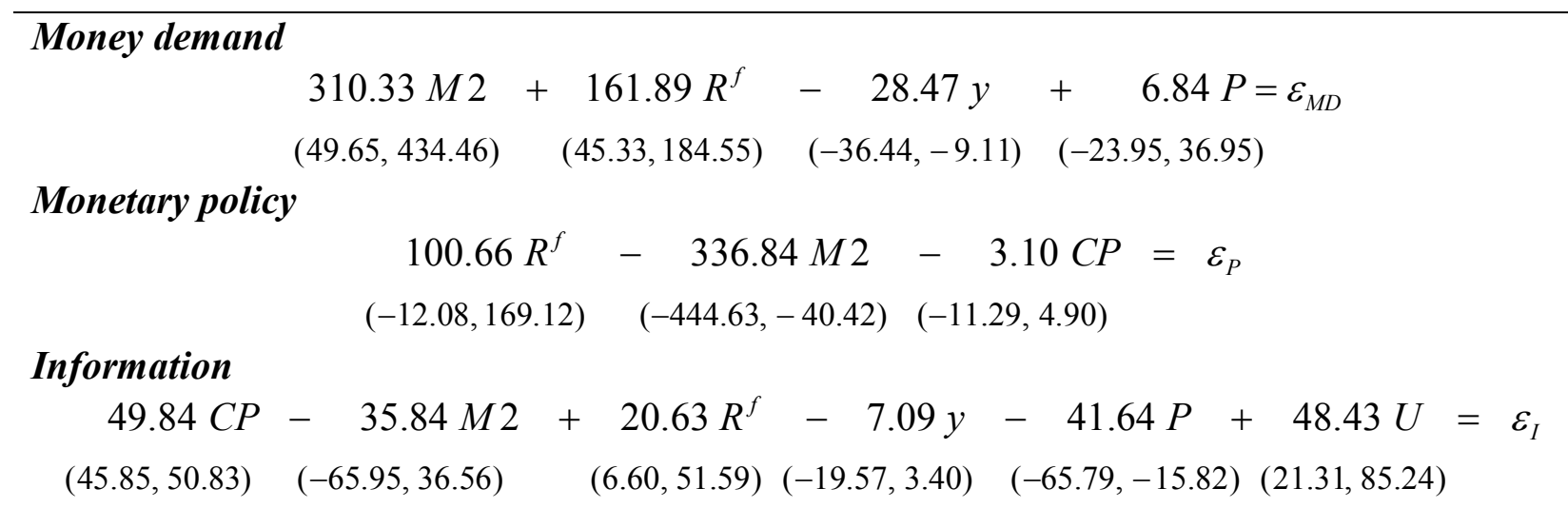

\section{Production sector}

This subsystem is arranged in the lower-triangular order $y, P$, and $U$.

68 percent probability intervals for the maximum likelihood estimates are reported in parentheses. Those intervals are based on exact finite-sample results computed by a Gibbs sampler algorithm with 360,000 Monte Carlo draws. See Waggoner and Zha (1998) for details.

\section{Table 4. Joint and Marginal Probabilities Conditional on Alternative Policies}

Outcomes Based on Out-of-Sample Forecasts from September 1990.

"Tighter" policy raises $R^{f}$ to $8.70 \%$ in October and to $8.95 \%$ in November 1990-January 1991 and is produced by the sequence of exogenous actions $\tilde{\varepsilon}_{P}=(2.3,1.7,1.0,0.9)$.

"Actual $R^{f}$ " sets $R^{f}$ at $8.11 \%$ in October, 7.81\% in November, 7.31\% in December, $6.91 \%$ in January 1991 and is produced by the sequence of exogenous actions $\tilde{\varepsilon}_{P}=(0.5,0.1,-0.7,-0.7)$.

\begin{tabular}{|c|c|c|}
\hline & Tighter & Actual $R^{f}$ \\
\hline$P($ low $\pi$ in 1992$)$ & .67 & .47 \\
\hline$P($ low $\pi$ in 1993$)$ & .66 & .46 \\
\hline$P($ low $\pi$ in 1992 and 1993$)$ & .57 & .36 \\
\hline$P($ recession in 1991$)$ & .53 & .27 \\
\hline$P($ recession in 1992) & .12 & .05 \\
\hline$P($ recession in 1993) & .05 & .06 \\
\hline$P($ recession and low $\pi)$ & .33 & .11 \\
\hline$P($ recession and high $\pi)$ & .25 & .22 \\
\hline$P($ no recession and low $\pi)$ & .24 & .25 \\
\hline$P($ no recession and high $\pi)$ & .18 & .42 \\
\hline
\end{tabular}

$P($ recession $)$ is the probability of negative real GDP growth in 1991 or 1992 or 1993.

$P($ low $\pi)$ is the probability of inflation below 51/2 percent in 1992 and 1993.

$P($ recession and low $\pi)$ is the probability of negative real GDP growth in 1991 or 1992 or 1993 and inflation below 51/2 percent in 1992 and 1993. 


\section{Figure 1. Impulse Responses in Fixed-Regime Model}

(Extreme Differences Policy Regime 1)

Percent Deviations from No Intervention Forecast
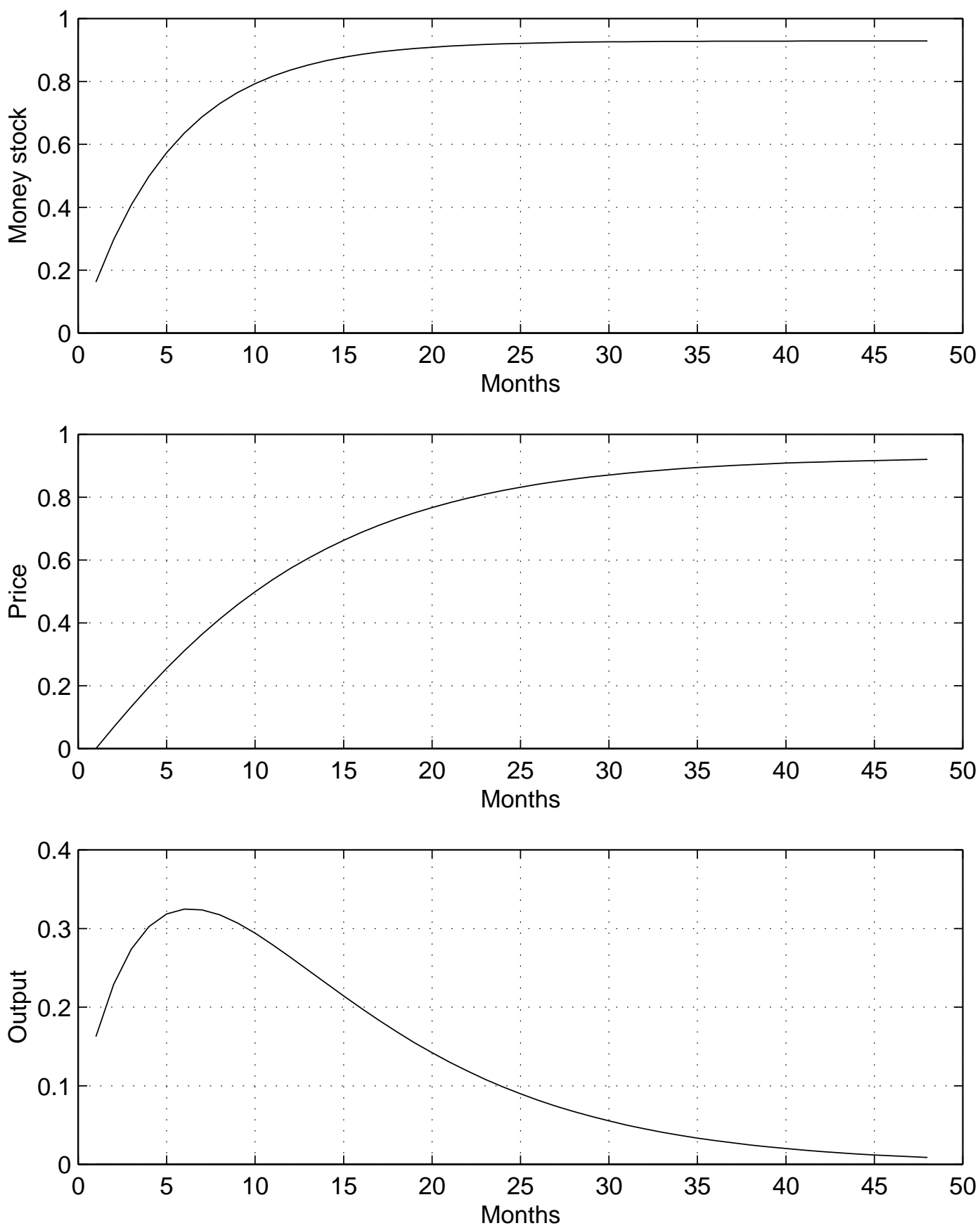


\section{Figure 2. Impacts of a Long Sequence of Small Interventions (Extreme Differences in Policy Regimes)}

$$
\text { Intervention }=(.667 \text { Standard Deviations } X 48 \text { Months })
$$
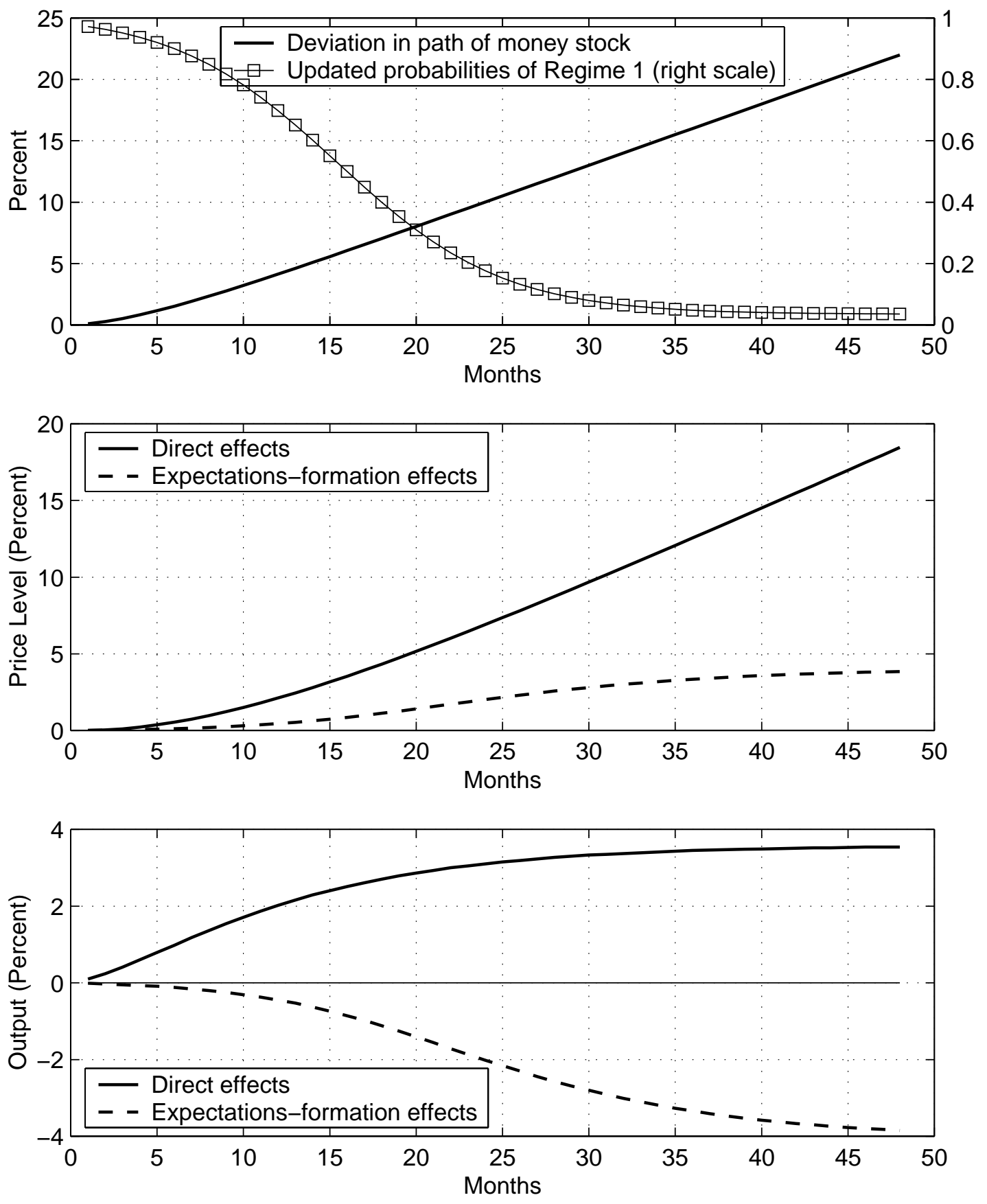


\section{Figure 3. Impacts of a Short Sequence of Large Interventions} (Extreme Differences in Policy Regimes)

$$
\text { Intervention }=\text { (8 Standard Deviations } X 4 \text { Months })
$$
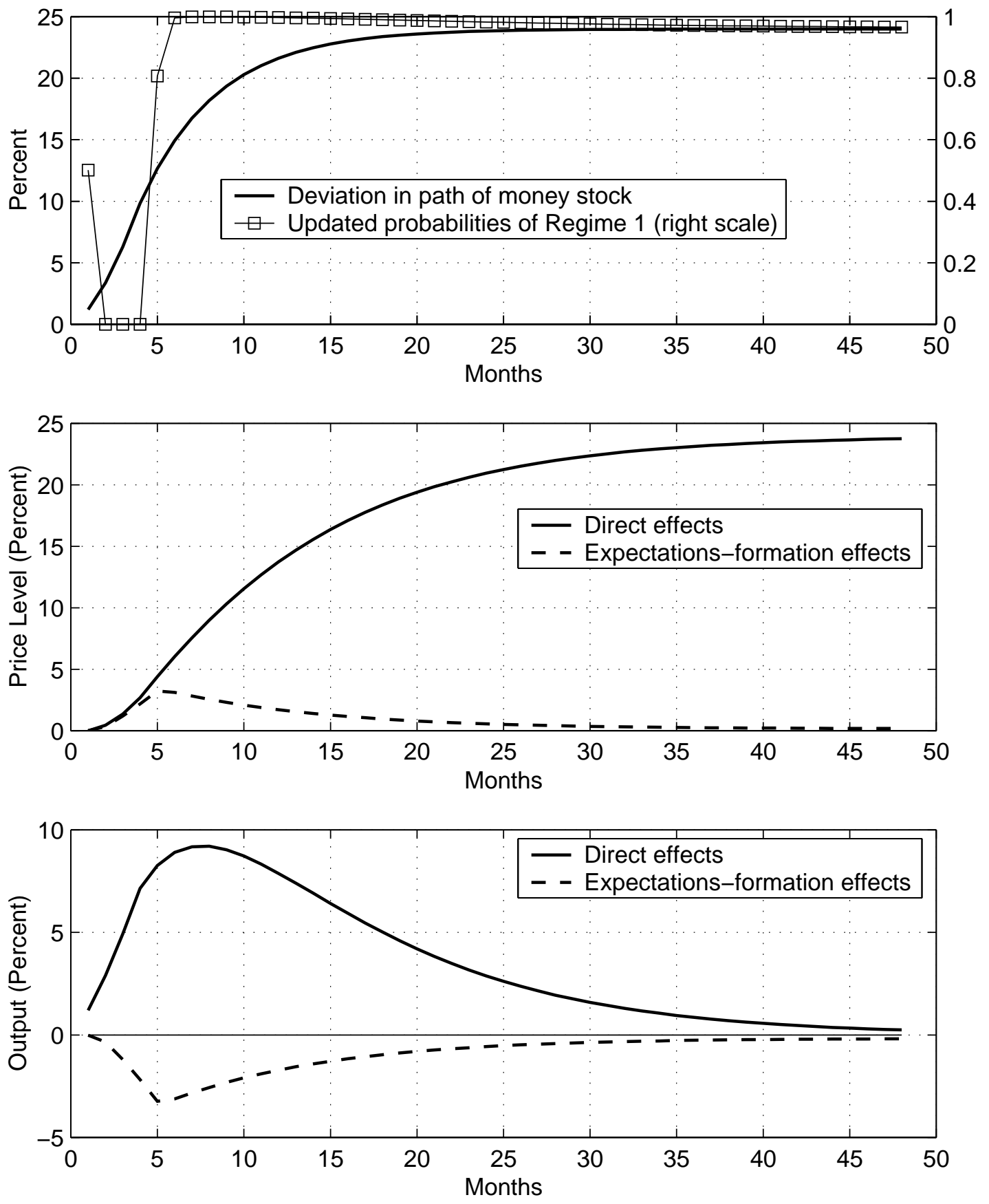


\section{Figure 4. Responses to an Exogenous Monetary Policy Contraction: Monthly}

Maximum likelihood estimates (solid) and 68\% probability bands (dashed). Log levels or percentage points.
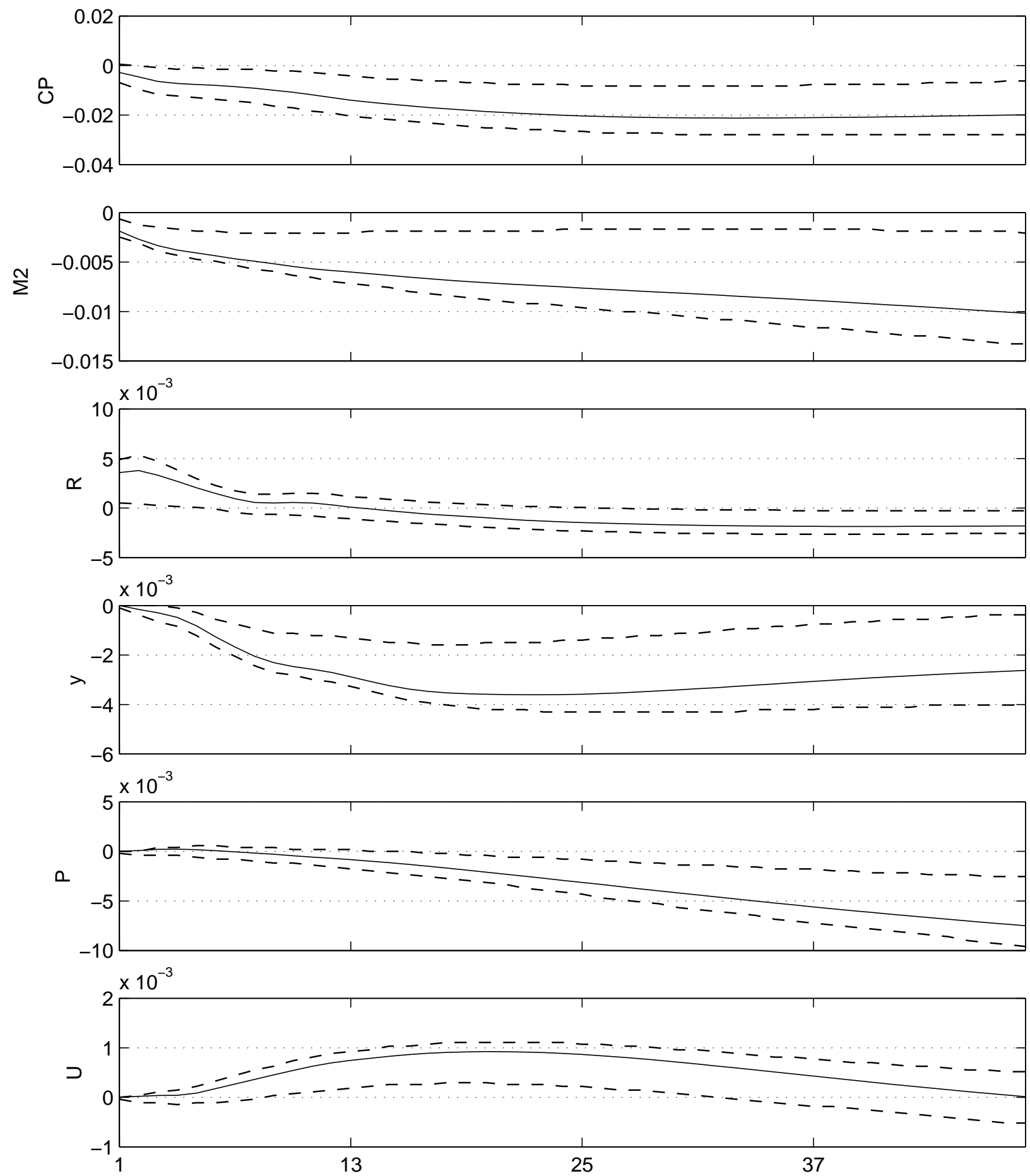
Figure 5. Forecasts Conditional on Actual Path of Funds Rate

Actual (solid) and out-of-sample forecast (dashed). Out-of-sample forecasts conditional on actual path of the federal funds rate from October 1990 to January 1991. Forecasts include maximum likelihood estimates (dashed-dot) and 68\% probability bands (dashed). Annual average growth rates or percentage points.
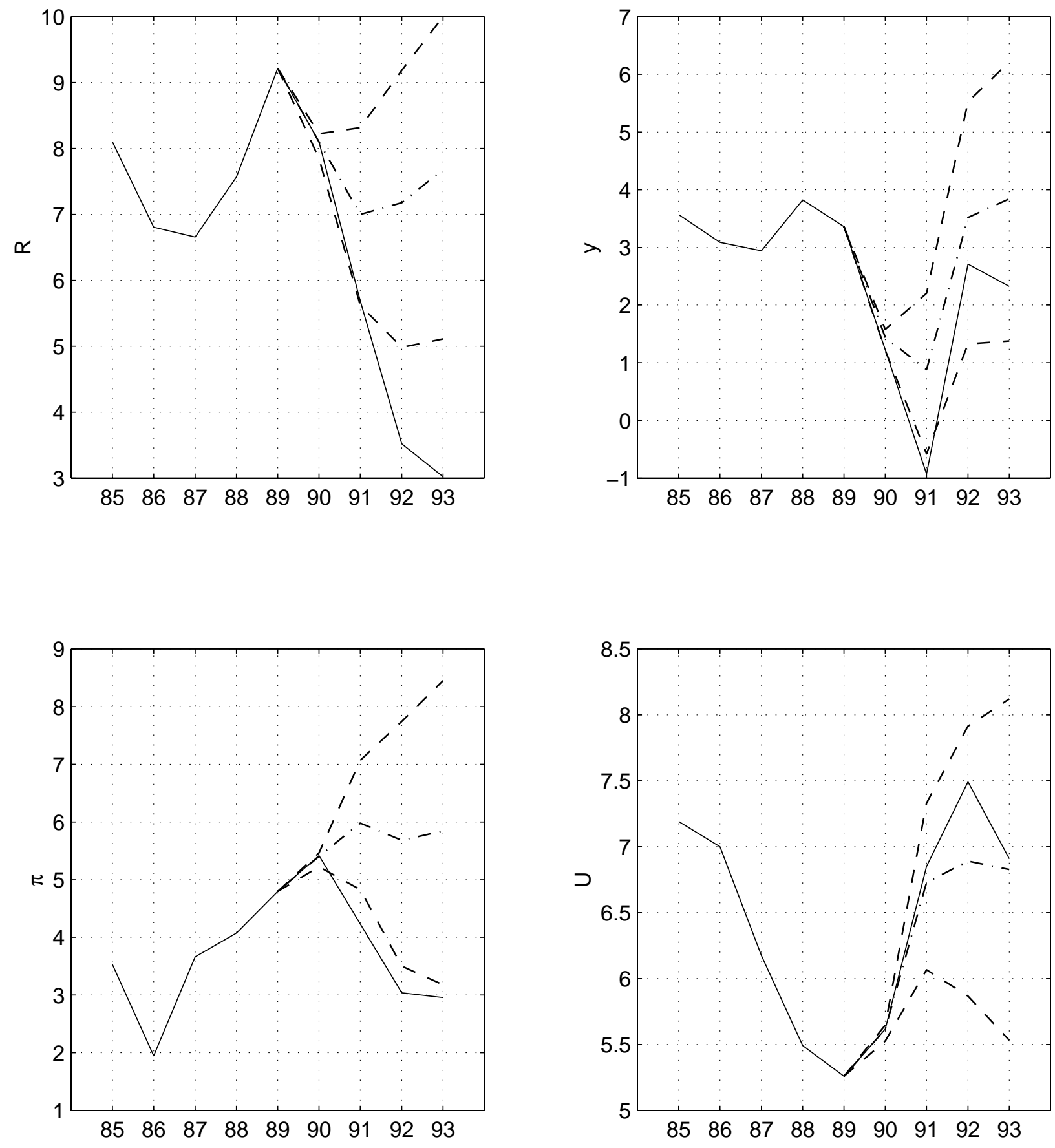


\section{Figure 6. Forecasts Conditional on Tighter Policy}

Actual (solid) and out-of-sample forecast (dashed). Out-of-sample forecasts conditional on tighter policy, raising the federal funds rate 50 basis points in October 1990 (to 8.70\%) and another 25 basis points over November 1990 to January 1991 (to 8.95\%). Forecasts include maximum likelihood estimates (dashed-dot) and $68 \%$ probability bands (dashed). Annual average growth rates or percentage points.
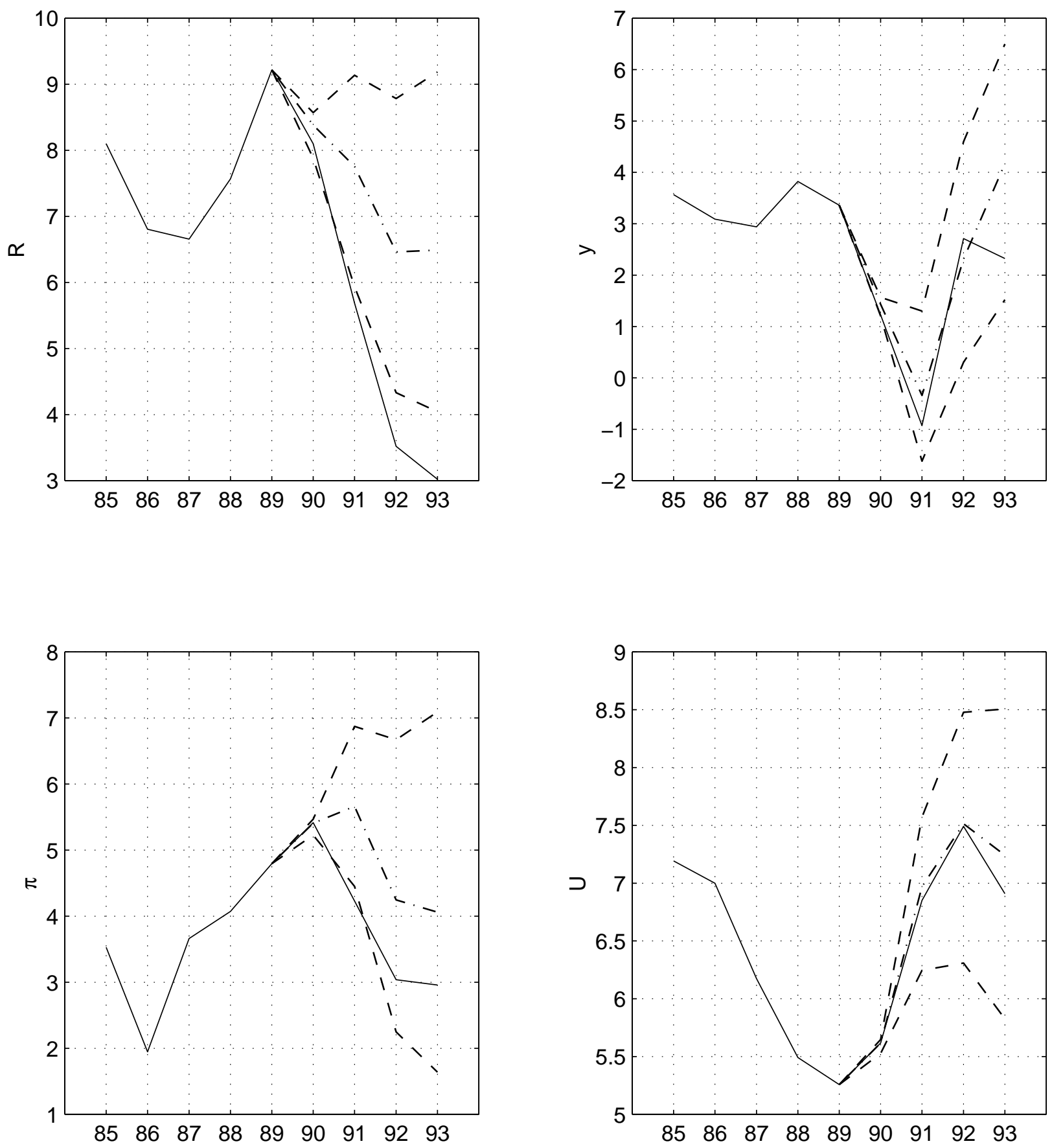
Figure 7. Forecasts Conditional on Constant and Actual Funds Rate: 94:2

Actual (solid) and out-of-sample forecasts conditional on a constant funds rate $(+)$ and on the actual path of the funds rate $\left(^{*}\right)$ from February to May 1994. Constant rate is $3.00 \%$; actual path is $3.25 \%, 3.34 \%, 3.56 \%, 4.01 \%$. Annual average growth rates or percentage points.
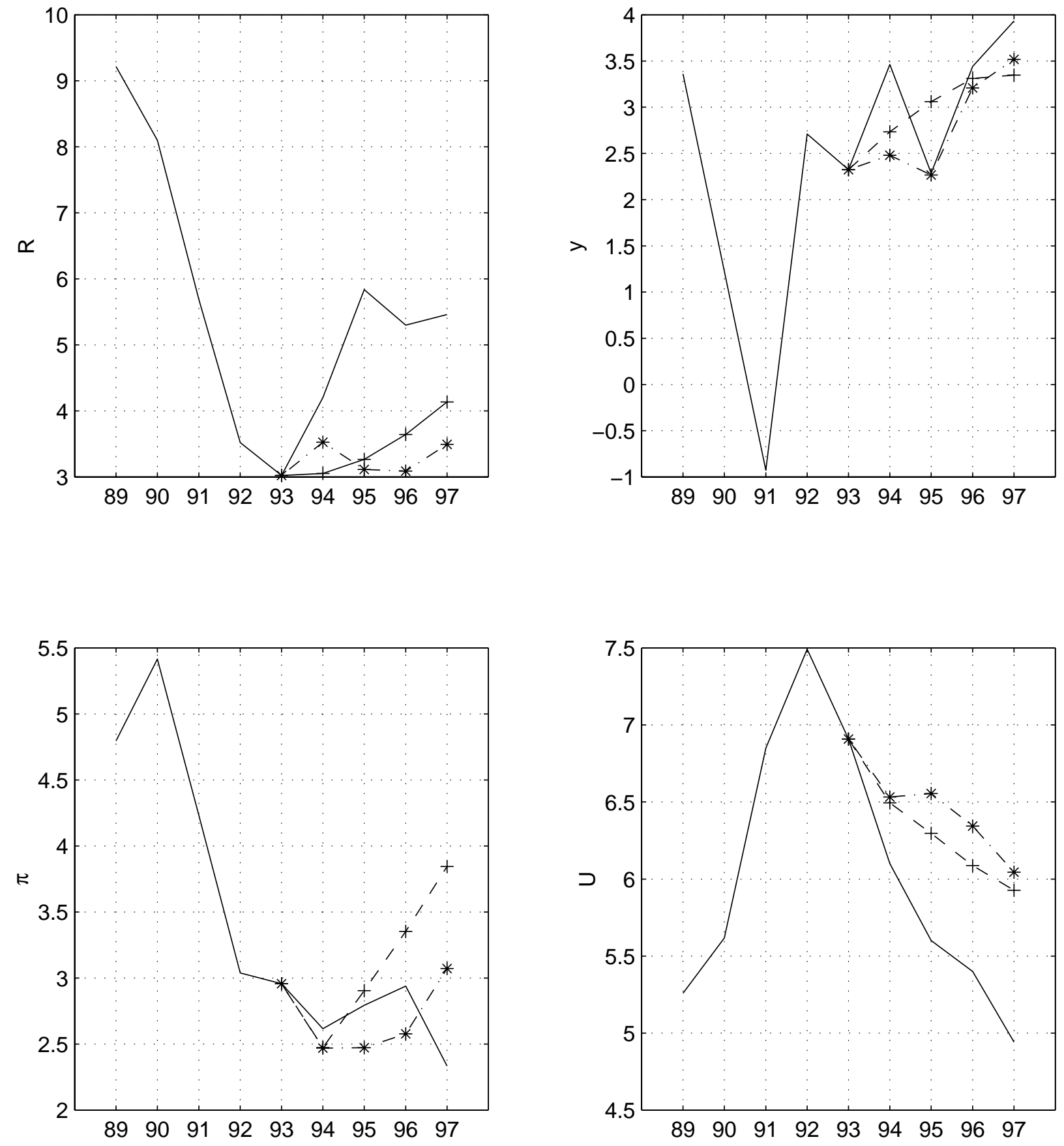
Figure 8. Forecasts Conditional on Constant and Actual Funds Rate: 94:5

Actual (solid line) and out-of-sample forecasts conditional on a constant funds rate $(+)$ and on the actual path of the funds rate $(*)$ from May to August 1994. Constant rate is 3.75\%; actual path is $4.01 \%, 4.25 \%, 4.26 \%, 4.47 \%$. Annual average growth rates or percentage points.
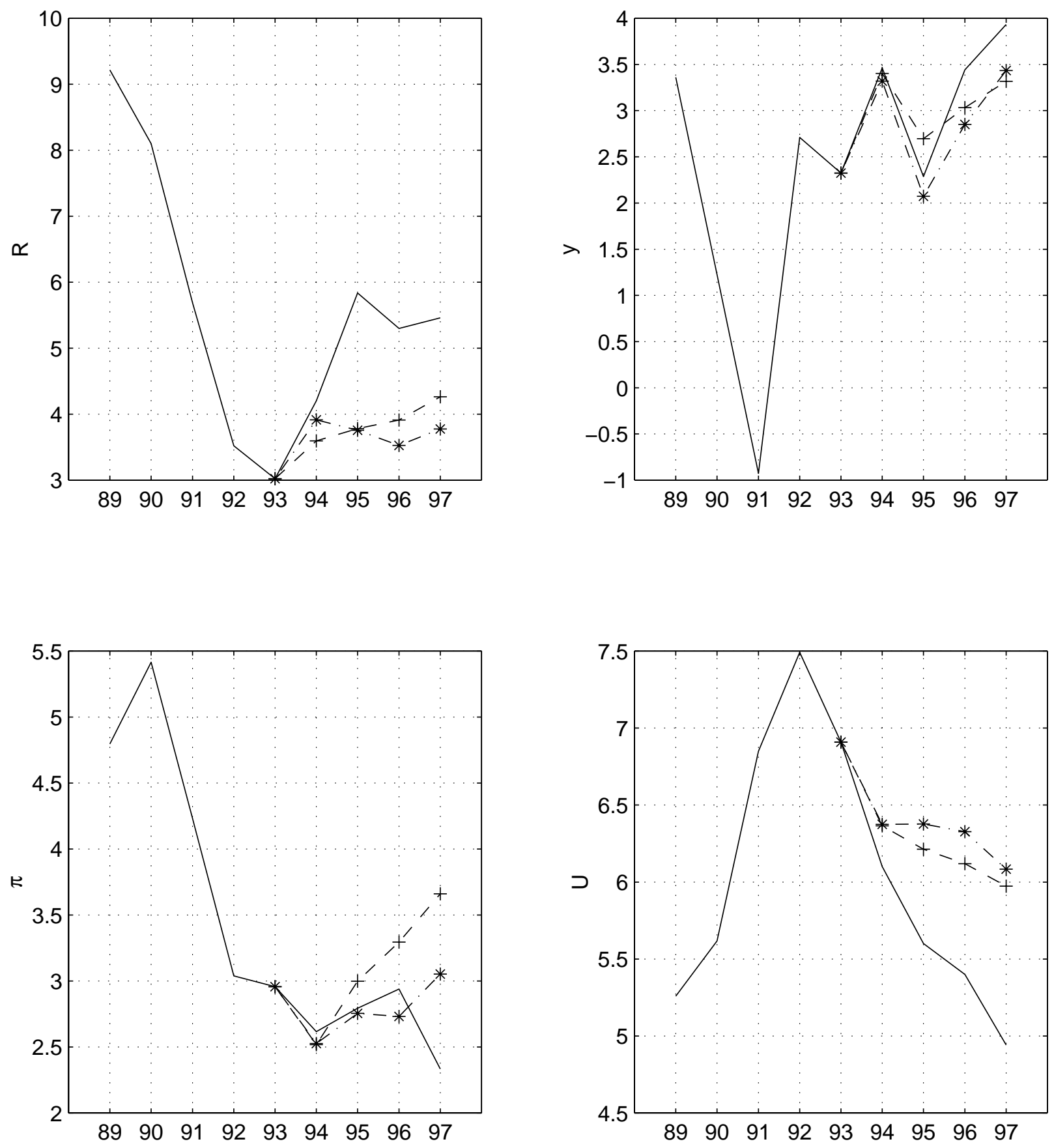


\section{References}

Andolfatto, David and Paul Gomme (2003). "Monetary Policy Regimes and Beliefs."

International Economic Review, Forthcoming.

Bank of England (2000). "Inflation Report," November. (London).

Bernanke, Ben S., Mark Gertler and Mark Watson (1997). "Systematic Monetary Policy and the Effects of Oil Price Shocks." Brookings Papers on Economic Activity 1, 91-142.

Blinder, Alan S. (1997). "What Central Bankers Could Learn from Academics--and Vice Versa." Journal of Economic Perspectives 11, 3-19.

Board of Governors of the Federal Reserve System (1999). "Press Release," May 18.

(Washington, D.C.).

Brainard, William C. (1967). "Uncertainty and the Effectiveness of Policy." American Economic Review 57, Papers and Proceedings, 411-425.

Cagan, Philip (1972). The Channels of Monetary Effects on Interest Rates. (New York: National Bureau of Economic Research).

Calvo, Guillermo A. (1983). "Staggered Prices in a Utility Maxmimizing Model." Journal of Monetary Economics 12, November, 383-398.

Cochrane, John H. (1998). "What Do the VARs Mean? Measuring the Output Effects of Monetary Policy." Journal of Monetary Economics 41, April, 277-300.

Cooley, Thomas F., Stephen F. LeRoy and Neil Raymon (1982). "Modeling Policy Interventions." Mimeo, University of California, Santa Barbara. December.

Cooley, Thomas F., Stephen F. LeRoy and Neil Raymon (1984). "Econometric Policy Evaluation: Note." American Economic Review 74, June, 467-470.

Doan, Thomas A., Robert B. Litterman and Christopher A. Sims (1984). "Forecasting and Conditional Projection Using Realistic Prior Distributions." Econometric Reviews 3, 1-100.

Friedman, Milton (1968). "The Role of Monetary Policy.” American Economic Review 58, March, 1-17.

Gordon, David B. and Eric M. Leeper (1994). "The Dynamic Impacts of Monetary Policy: An Exercise in Tentative Identification." Journal of Political Economy 102, 1228-1247.

Hamilton, James D. (1989). "A New Approach to the Economic Analysis of Nonstationary Time Series and the Business Cycle." Econometrica 57, March, 357-384.

Hamilton, James D. (1994). Time Series Analysis. (Princeton: Princeton University Press).

Hamilton, James D. and Ana Maria Herrera (2002). "Oil Shocks and Aggregate Macroeconomic Behavior: The Role of Monetary Policy." Journal of Money, Credit, and Banking, Forthcoming.

Jansson, Per and Anders Vredin (2000). "Forecast-Based Monetary Policy in Sweden 19921998." Mimeo, Sveriges Riksbank. December.

Kohn, Donald L. (1995). "Comment on 'Inflation Indicators and Inflation Policy' by Cecchetti." In NBER Macroeconomics Annual 1995, Ben S. Bernanke and Julio J. Rotemberg, eds. (Cambridge, MA: MIT Press): 227-233.

Leeper, Eric M., Christopher A. Sims and Tao Zha (1996). "What Does Monetary Policy Do?" Brookings Papers on Economic Activity 2, 1-63.

Leeper, Eric M. and Tao Zha (2002). "Empirical Analysis of Policy Interventions," NBER Working Paper No. 9063. 
Lucas, Jr., Robert E. (1972). "Econometric Testing of the Natural Rate Hypothesis." In The Econometrics of Price Determination Conference, Otto Eckstein, ed. (Washington, D.C.: Board of Governors of the Federal Reserve System): 50-59.

Lucas, Jr., Robert E. (1973). "Some International Evidence on Output-Inflation Tradeoffs." American Economic Review 63, 326-334.

Lucas, Jr., Robert E. (1976). “Econometric Policy Evaluation: A Critique.” In CarnegieRochester Conference Series on Public Policy 1, Karl Brunner and Allan H. Meltzer, eds. (Amsterdam: North-Holland): 104-130.

Marschak, Jacob (1953). "Economic Measurements for Policy and Prediction." In Studies in Econometric Method, William C. Hood and Tjalling C. Koopmans, eds. (New York: Wiley): $1-26$.

Rotemberg, Julio J. (1982). "Sticky Prices in the United States." Journal of Political Economy 90, December, 1187-1211.

Rotemberg, Julio J. (1996). "Prices, Output, and Hours: An Empirical Analysis Based on a Sticky Price Model." Journal of Monetary Economics 37, June, 505-533.

Sargent, Thomas J. (1984). "Vector Autoregressions, Expectations, and Advice." American Economic Review 74, May, 408-415.

Sargent, Thomas J. (1999). The Conquest of American Inflation. (Princeton, NJ: Princeton University Press).

Sims, Christopher A. (1982). "Policy Analysis with Econometric Models." Brookings Papers on Economic Activity 1, 107-152.

Sims, Christopher A. (1987). "A Rational Expectations Framework for Short-Run Policy Analysis." In New Approaches to Monetary Economics, William A. Barnett and Kenneth J. Singleton, eds. (Cambridge, UK: Cambridge University Press): 293-308.

Sims, Christopher A. (1998). "The Role of Interest Rate Policy in the Generation and Propagation of Business Cycles: What Has Changed Since the '30s?' In Beyond Shocks: What Causes Business Cycles?, Jeffrey C. Fuhrer and Scott Schuh, eds. (Boston: Federal Reserve Bank of Boston): 121-160.

Sims, Christopher A. and Tao Zha (1998). "Does Monetary Policy Generate Recessions?" Mimeo, Federal Reserve Bank of Atlanta, July.

Sims, Christopher A. and Tao Zha (1999). "Error Bands for Impulse Responses." Econometrica 67, September, 1113-1155.

Sveriges Riksbank (1999). "Inflation Report,” March. (Stockholm).

Waggoner, Daniel F. and Tao Zha (1998). "Does Normalization Matter for Inference?” Mimeo, Federal Reserve Bank of Atlanta. 